\title{
FISIOTERAPIA EM TEMPOS DE PANDEMIA: \\ A TECNOLOGIA NAS INTER-RELAÇÕES DOCENTE, ALUNO E PACIENTE
}

Série Material Instrucional UDESC

\section{OP UDITERA}


Série Material Instrucional UDESC

FISIOTERAPIA EM TEMPOS DE PANDEMIA:

A TECNOLOGIA NAS INTER-RELAÇÕES

DOCENTE, ALUNO E PACIENTE

Florianópolis/SC

UDESC

2020 


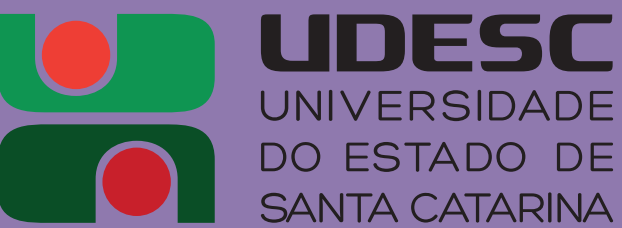

Dilmar Baretta

Reitor

Luiz Antonio Ferreira Coelho

Vice-Reitor

Marilha dos Santos

Pró-Reitora de Administração

Márcio Metzner

Pró-Reitor de Planejamento

Nerio Amboni

Pró-Reitor de Ensino

Mayco Morais Nunes

Pró-Reitor de Extensão, Cultura e Comunidade

Leticia Sequinatto

Pró-Reitora de Pesquisa e Pós-Graduação

Editora UDESC

Marcia Silveira Kroeff | Coordenadora

\section{Conselho Editorial}

Marcia Silveira Kroeff | Presidente

Samira Kauchakje | CESFI

Gilmar Moraes Santos | CEFID

Giovanni Lemos de Mello | CERES

Avanilde Kemczinski | CCT

Sandra Regina Rech | CEART

Delcio Pereira | CEPLAN

Fabiano Maury Raupp | ESAG

Marilei Kroetz | CEAVI

William Campo Meschial | CEO

Jordan Paulesky Juliani | CEAD

Fernando Coelho | FAED

Roseli Lopes da Costa Bortoluzzi | CAV

\section{Editora UDESC}

Fone: (48) 3664-8100

E-mail: editora@udesc.br

http://www.udesc.br/editorauniversitaria 


\section{REVISORES DO Conteúdo}

Debora Soccal Schwertner

Elaine Paulin Ferrazeane

Fernanda Romaguera Pereira dos Santos

Luciana Sayuri Sanada

Micheline Henrique Araujo da Luz Koerich

\section{AUTORES}

Debora Soccal Schwertner

Fernanda Romaguera Pereira dos Santos

Luciana Sayuri Sanada

Micheline Henrique Araujo da Luz Koerich

Ana Beatriz Roque

André Luís Ferreira de Meireles

Eduarda Pelisser Campos

Fabio Sprada

Juliane Oliveira

Juliano Tibola

Katerine Cani

Mirella Dias

Rodrigo José Knabben

Sabrina Fortes Pereira

Uriel Jandt

Vitória Kuhn

Vanessa Zeni Refosco

\section{CONTRIBUIÇÕES INSTITUCIONAIS}

Departamento de Fisioterapia | UDESC

Núcleo Docente Estruturante do

Departamento de Fisioterapia | UDESC

Capa e Projeto Gráfico

Mauro Tortato

DIAGRAMAÇÃO

Chris Dalla Costa

RevisÃo Editorial Linguística e Ortográfica Janete Gheller

DOI 10.5965/978-65-88565-25-4

F537 Fisioterapia em tempos de pandemia: tecnologia nas inter-relações docentes, aluno e paciente / Debora Soccal Schwertner et al.; capa e projeto gráfico Mauro Tortato; diagramação Chris Dalla Costa; revisão editorial linguística e ortográfica Janete Gheller. - Florianópolis: UDESC, 2020. (Material Instrucional UDESC).

121 p. : il.; $21 \mathrm{~cm}$

ISBN-e: 978-65-88565-25-4

Referências: p. 118.

1. Fisioterapia. 2. Tecnologia médica - Santa Catarina. 3. Covid-19 (Doença). I. Schwertner, Debora Soccal. II. Tortato, Mauro. III. Dalla Costa, Chris. IV. Gheller, Janete. V. Cefid UDESC.

DOI:

Versão digital: 10.5965/978-65-88565-25-4.

CDD: 615.82 - 20. ed

Ficha catalográfica elaborada pela Bibliotecária Alice de A. B. Vazquez CRB 14/865

Biblioteca da UDESC 


\section{SUMÁRIO}

1 CONTEXTUALZAÇ̃̃O

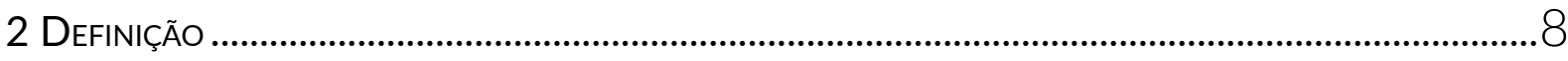

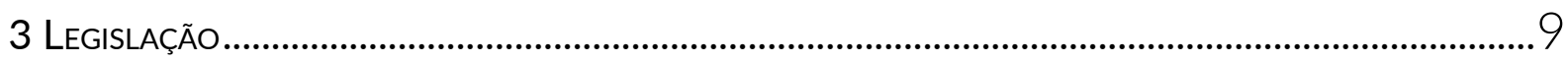

3.1 Regulamentação das atividades de atendimento aos pacientes ...............................

3.2 Regulamentação das atividades de ensino.................................................................11

3.2.1 Regulamentação MEC .....................................................................................11

3.2.2 Código de ética, diretrizes curriculares e PPC da Fisioterapia....................12

3.3 Privacidade e sigilo de informações..............................................................................

3.4 Possibilidades de encaminhar materiais de orientação aos pacientes...................14

3.5 Comprovação de atendimento..................................................................................... 14

3.6 Termo de consentimento e prontuário.........................................................................

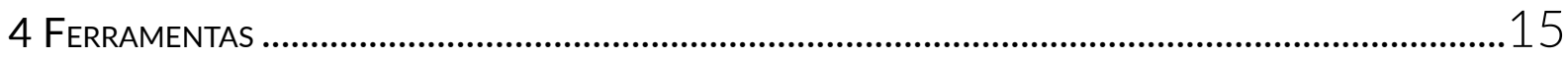

5 FACILITADORES E BARREIRAS PARA O USO DA TELECONSULtA/TELEMONITORAMENTO

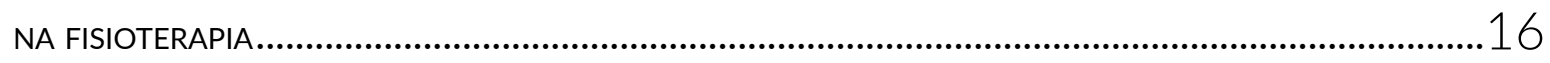

5.1 Facilitadores para a teleconsulta/telemonitoramento na fisioterapia...................17

5.1.1 Recursos tecnológicos..................................................................................... 17

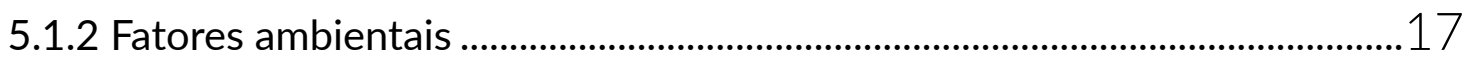

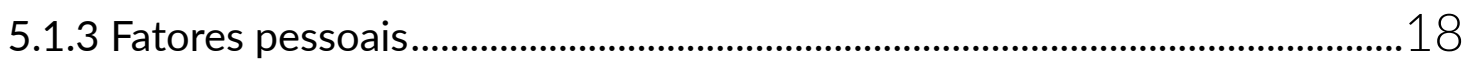

5.2 Barreiras para o uso da teleconsulta/telemonitoramento na fisioterapia............18

6 REGULAÇÃO DOS PACIENTES......................................................................................................19

7 HABILIDADES E COMPETÊNCIAS NECESSÁRIAS AO PROFESSOR E AO ALUNO QUE ATUARÃO COM A TELECONSULTA/TELEMONITORAMENTO NA FISIOTERAPIA ...............................................................2.

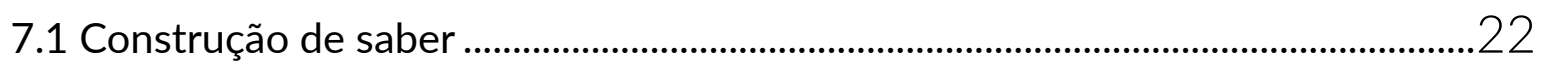

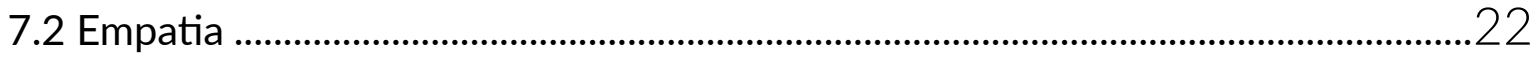

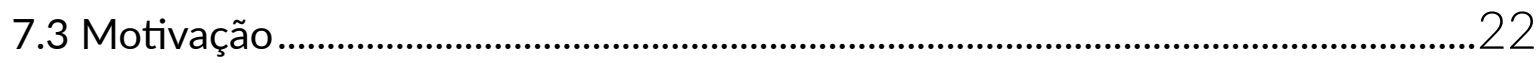

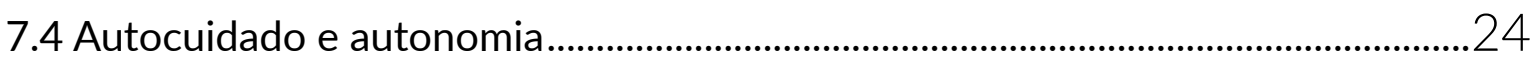

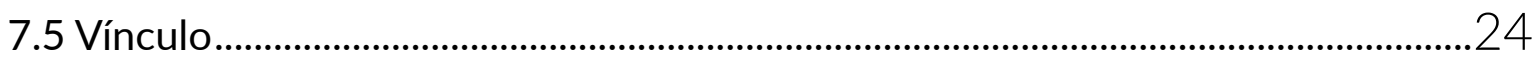

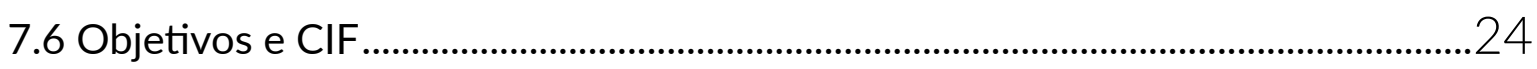

7.7 Valorização do conhecimento prévio/contexto ......................................................25

7.8 Elementos de Comunicação .................................................................................22

7.9 Conhecimento técnico e embasamento científico ...................................................26 
8 Plano de tratamento em teleconsulta/telemonitoramento na fisioterapia ........................26

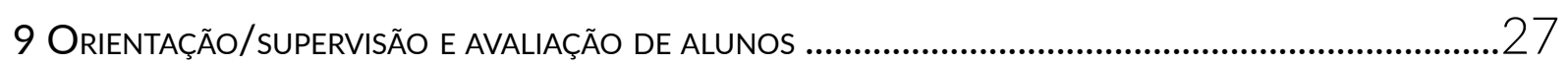

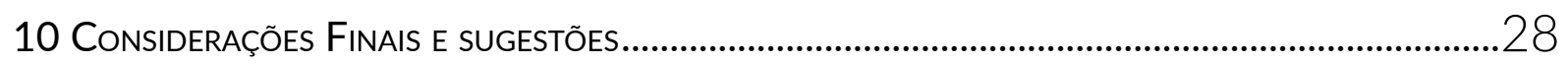

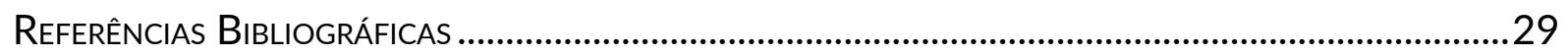

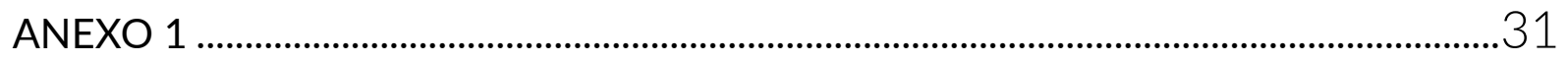

Modelo de termo de consentimento - sugestão para uso em atividades de ensino

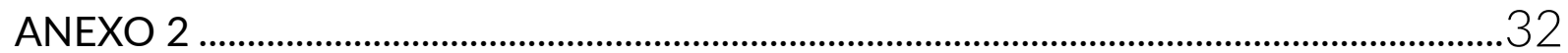

Modelo de checklist para verificação da admissibilidade do uso da teleconsulta/ telemonitoramento na fisioterapia em atividades de ensino

ANEXO 3

Questionário elaborado para determinar a regulação de pacientes nas disciplinas práticas

ANEXO 4

Sugestão de roteiro para a realização de teleconsulta/telemonitoramento na fisioterapia

ANEXO 5

Tabela com os dados de regulação dos pacientes das fases 6a, 7a e 8a do curso de Fisioterapia CEFID/UDESC 


\section{CONTEXTUALIZAÇÃO}

Em março de 2020, a Organização Mundial da Saúde (OMS) comunicou ao mundo a pandemia pela proliferação do patógeno SARS-CoV-2 (novo corona vírus) que, ao infectar o ser humano causa a doença COVID-19 (SAÚDE, 2020). Devido ao fácil contágio, várias medidas de combate à pandemia foram divulgadas e implantadas, dentre elas o distanciamento social, a recomendação de fechamento dos estabelecimentos, o isolamento em casa, entre outras. (CONSELHO NACIONAL DE SECRETÁRIOS DE SAÚDE; CONSELHO NACIONAL DE SECRETARIAS MUNICIPAIS DE SAÚDE; ORGANIZAÇÃO PAN-AMERICANA DE SAÚDE - OPAS/OMS, 2020). Com isso, as universidades suspenderam as aulas e interromperam os atendimentos à comunidade; consultórios e clínicas de Fisioterapia fecharam as portas e muitas pessoas ficaram desassistidas. Tendo em vista que a situação atual é de grande imprevisibilidade, pois não se sabe quando a pandemia terminará e de que forma poderemos retomar as atividades, os Fisioterapeutas, bem como as entidades representativas, têm se preocupado em oferecer à população algum tipo de atenção à saúde.

Neste sentido, o curso de Fisioterapia do Centro de Ciências da Saúde e do Esporte (CEFID) da Universidade do Estado de Santa Catarina (UDESC), considerando a sua responsabilidade social e ética com a comunidade e principalmente com os usuários em atendimento, está buscando opções para fornecer aos pacientes, durante este período de excepcionalidade, uma forma alternativa de cuidado. A maior preocupação está centrada em oferecer um serviço de qualidade, mas considerando que muitos pacientes, professores e alunos são pessoas de grupos de risco, essa atenção à saúde não pode facilitar a contaminação, ou seja, o atendimento presencial está, por hora, descartado.

O uso de tecnologias digitais parece ser uma ferramenta eficaz para auxiliar no atendimento/consulta fisioterapêutica em consultórios e clínicas particulares em vários países, incluindo o Brasil, bem como em aulas/estágios em universidades fora do Brasil. A Universidade de Queensland (Austrália), por exemplo, já desenvolve há anos parte do estágio na forma de telerreabilitação. $O$ objetivo é oferecer aos alunos um conjunto crescente de habilidades em telessaúde, desde a teoria e aspectos práticos da prestação de serviços on-line, até a apresentação de cenários clínicos, discussões de casos e estágio prático. (LEE et al., 2018).

O grupo de trabalho "Telerreabilitação" do Núcleo Docente Estruturante (NDE) Fisioterapia CEFID/UDESC surgiu da necessidade de identificar o que é esse serviço, como funciona, diagnosticar as barreiras e responder as questões: A "telerreabilitação" pode ser usada como atividade para atendimento aos pacientes nas disciplinas práticas e estágios? É viável?

Este documento foi embasado em uma extensa revisão de literatura, depoimentos de Fisioterapeutas que já adotaram a telerreabilitação em sua prática, bem como Lives [Instagram, Associação Brasileira de Ensino em Fisioterapia (https://www.instagram.com/tv/CAeCIRApPTj/?hl=pt-br) Conselho Regional De Fisioterapia E Terapia Ocupacional (CREFITO) 3 e 4 (https://www.instagram.com/ tv/CAl4aOKJK8V/), profissionais], participação em reuniões em que esta temática foi trabalhada, folders, manuais de trabalho entre outros. 


\section{DEFINIÇÃO}

O termo telerreabilitação estava sendo empregado mesmo antes da pandemia, para designar um conjunto de atividades relacionadas ao cuidado da saúde de pacientes, nas quais era usada uma variedade de tecnologias. No Brasil, o início das atividades voltadas à saúde, usando plataformas digitais teve início em 2010 com o Programa Telesaúde, no Rio de Janeiro, que desenvolveu principalmente atividades informativas e de capacitação (CREFITO 2).

Da mesma forma, em 2017, a World Confederation of Physical Therapy criou um grupo de trabalho para definir diretrizes para que os profissionais de diferentes lugares do mundo pudessem se adaptar à atual realidade que envolve a internet, proporcionando atendimento de qualidade em momentos de distanciamento entre as partes. Em 2019, criaram um documento que visava facilitar a entrega efetiva de serviços de fisioterapia, tendo por objetivo o provimento de cuidado e informações aos pacientes (WCPT, 2019). Considerando essa tendência, muito embora o Conselho Federal de Fisioterapia e Terapia Ocupacional (COFFITO) ainda não permitisse até a pandemia as práticas de atendimentos virtuais, especialistas em Tecnologia da Informação (TI) já garantiam que havia forte inclinação à aceitação destas ferramentas como forma de atenção aos pacientes com limitações ao deslocamento, entre outros usos.

Além de telerreabilitação, o uso das ferramentas digitais no atendimento aos pacientes tem outras nomenclaturas: telesaúde, tele-educação, telemonitoramento, teleassistência, saúde móvel, entre outros. O COFFITO adotou os termos teleconsulta, telemonitoramento e teleconsultoria (RESOLUÇÃO COFFITO 516/2020, descrição Quadro 1).

No presente documento, adotar-se-á o termo "telefisioterapia", pois ao mesmo tempo em que é abrangente e envolve todas as competências da profissão, permite que o Fisioterapeuta tenha liberdade para escolher e trabalhar com a atividade mais adequada ao paciente - avaliação, atividades de educação, orientações, tratamento e prevenção, etc. (SILVA, 2010; FLORENTINO, SILVA, SOUZA, 2017). Além disto, a exemplo da telemedicina e teleodontologia, terminologias já usadas pelas respectivas profissões que creditam ao profissional o que é de sua atribuição, a telefisioterapia determina ao Fisioterapeuta sua apropriação às atividades que são exclusivamente de sua competência.

O atendimento Fisioterapêutico presencial, a Telefisioterapia têm características diferentes, não compartilham os mesmos objetivos, formas de avaliação, tão pouco das mesmas técnicas e métodos terapêuticos, contudo estão sujeitos aos mesmos preceitos éticos (Resolução COFFITO 424/2013) no atendimento ao paciente (confidencialidade, sigilo, cuidados com a documentação, respeito). As ferramentas digitais não buscam substituir o atendimento presencial, mas dar ao paciente alguma forma de atendimento possível neste momento.

Logo, para que se possa implantar a teleconsulta e o telemonitoramento, há algumas questões que precisam ser planejadas: infraestrutura da Instituição e dos pacientes (espaço físico, materiais disponíveis, internet, celular, computador), logística de transferência de dados, questões legais, sociais (idade, grau de escolaridade, conhecimentos de informática) e éticas (privacidade e confidencialidade), capacitação profissional (avaliação e tratamento de forma remota) e aprimoramento das formas de supervisionar/orientar os alunos. 


\section{LEGISLAÇÃO}

\subsection{REGULAMENTAÇÃO DAS ATIVIDADES DE ATENDIMENTO AOS PACIENTES}

Neste momento o Brasil ainda não possui legislações específicas que regulamentem a Telefisioterapia/telerreabilitação. Por enquanto, o Conselho Federal de Fisioterapia e Terapia Ocupacional (COFFITO), de acordo com suas atribuições, estabeleceu alguns critérios que envolvem, conforme nossas expectativas, diretrizes não muito claras à adoção desta atividade - Resolução COFFITO n. 516, de 23 de março de 2020 (Quadro 1).

\section{QuAdRO 1 | Resolução COFFITO 516/2020}

RESOLUÇÃO № 516, DE 20 DE MARÇO DE 2020

Teleconsulta, Telemonitoramento e Teleconsultoria

Dispõe sobre a suspensão temporária do Artigo 15, inciso II e Artigo 39 da Resolução COFFITO no 424/2013 e Artigo 15, inciso Il e Artigo 39 da Resolução COFFITO no 425/2013 e estabelece outras providências durante o enfrentamento da crise provocada pela Pandemia do COVID-19.

O Presidente do Conselho Federal de Fisioterapia e Terapia Ocupacional - COFFITO, no uso de suas atribuições legais, conferidas pela Lei no 6.316/75 de 17 de dezembro de 1975 e disposições regulamentares, ad referendum do Plenário do Conselho Federal de Fisioterapia e Terapia Ocupacional;

CONSIDERANDO a classificação da Organização Mundial da Saúde (OMS) no dia 11 de março de 2020, como pandemia o novo coronavírus - COVID-19;

CONSIDERANDO a competência legal estatuída na norma do art. 5, incisos II e XII da Lei Federal no 6.316/75;

CONSIDERANDO a gravidade e rapidez com que a epidemia se espalhou em diversos países e no Brasil, resolve:

Artigo 1- Suspender os efeitos do art. 15, inciso II da Resolução COFFITO no 424, de 08 de julho de 2013 e do art. 15, inciso II da Resolução COFFITO no 425, de 08 de julho de 2013.

Artigo $2{ }^{\circ}$ A permissão para atendimento não presencial se dará apenas nas modalidades, teleconsulta, teleconsultoria e telemonitoramento.

$\S 1$ - A Teleconsulta consiste na consulta clínica registrada e realizada pelo Fisioterapeuta ou Terapeuta Ocupacional à distância.

$\S 2$ - O Telemonitoramento consiste no acompanhamento à distância de paciente atendido previamente de forma presencial, por meio de aparelhos tecnológicos. Nesta modalidade, - Fisioterapeuta ou Terapeuta Ocupacional pode utilizar métodos síncronos e assíncronos, como também deve decidir sobre a necessidade de encontros presenciais à reavaliação, sem- 
pre que necessário, podendo também ser feito, de comum acordo, por outro Fisioterapeuta ou Terapeuta Ocupacional local.

§ 3 A Teleconsultoria consiste na comunicação registrada e realizada entre profissionais, gestores e outros interessados da área de saúde, fundamentada em evidências clínico-científicas e em protocolos disponibilizados pelo Ministério da Saúde e pelas Secretarias Estaduais e Municipais de Saúde, com o fim de esclarecer dúvidas sobre procedimentos clínicos, ações de saúde e questões relativas ao processo de trabalho.

$\S 4$ - O Fisioterapeuta ou Terapeuta Ocupacional tem autonomia e independência para determinar quais pacientes ou casos podem ser atendidos ou acompanhados à distância; tal decisão deve ser baseada em evidências científicas no benefício e na segurança de seus pacientes.

Artigo 3- A prestação dos serviços na forma do art. 2ㅇ desta Resolução poderá ser de forma síncrona ou assíncrona:

a. Síncrona: qualquer forma de comunicação à distância realizada em tempo real;

b. Assíncrona: qualquer forma de comunicação à distância não realizada em tempo real.

Artigo 4ํ Na prestação dos serviços não presenciais, o profissional está obrigado a observar todos os demais dispositivos contidos nos Códigos de Ética e Deontologia da Fisioterapia e da Terapia Ocupacional, além das demais normas do COFFITO.

Artigo 5 Os serviços prestados à distância em Fisioterapia e Terapia Ocupacional deverão respeitar a infraestrutura tecnológica física, recursos humanos e materiais adequados, assim como obedecer às normas técnicas de guarda, manuseio e transmissão de dados, garantindo confidencialidade, privacidade e sigilo profissional semelhantes ao atendimento presencial.

Artigo 6o Suspender os efeitos do art. 39 da Resolução COFFITO no 424, de 08 de julho de 2013 e do art. 39 da Resolução COFFITO no 425, de 08 de julho de 2013.

Parágrafo único. O profissional fica autorizado a realizar e prestar serviços de forma gratuita, sem a cobrança de honorários, cabendo a decisão quanto à graciosidade do atendimento a cada profissional.

Artigo 7ํ A presente Resolução será submetida ao referendo do Plenário do COFFITO na primeira oportunidade em que seja possível a realização de reunião plenária.

Artigo 8 A presente Resolução poderá ser alterada a qualquer momento, podendo ser editados novos atos normativos à regulação da matéria aqui prevista.

Artigo 9o Esta Resolução entra em vigor na data de sua publicação.

\section{ROBERTO MATTAR CEPEDA}

Publicado no Diário Oficial da União no dia 23 de março de 2020.

Fonte: COFFITO, 2020 (https://www.coffito.gov.br/nsite/?p=15825)

* Grifo dos autores 
Esta resolução, apesar de garantir o acolhimento aos pacientes que ficaram sem atendimento e nortear algumas atividades, restringe a atuação do Fisioterapeuta e possibilita diferentes entendimentos quanto às atividades que podem ser exercidas. $O$ uso de teleconsulta, por exemplo, dá margem a várias interpretações; em uma Live no dia 24/5/2020, o presidente do CREFITO 4 e o advogado deste Conselho observaram que pode ser considerada como sinônimo de avaliação, enquanto muitas pessoas compreendem que a avaliação fica limitada. Sobre telemonitoramento, considerando a questão de restringir ou não o atendimento a pacientes novos, o CREFITO 4 acredita que se aplica o princípio da razoabilidade; as normas não podem ser inflexíveis e cabe ao Fisioterapeuta avaliar se há condições de realizar atendimento à distância em pacientes novos.

Acredita-se que leis e diretrizes mais específicas deverão ser redigidas e implantadas a fim de garantir, de forma mais clara, as atividades do Fisioterapeuta, o papel das Instituições de Ensino Superior (IES) no atendimento aos pacientes, bem como direitos e deveres de ambas as partes (paciente e profissional).

Atualmente, está tramitando o Projeto de Lei 1494/20 pela qual é permitido o atendimento na modalidade telessaúde para fisioterapeutas e terapeutas ocupacionais enquanto durar a pandemia de Covid-19, mas no teor do texto não estão regimentadas claramente estas atividades, ao contrário, reforça o papel do COFFITO na regulamentação do atendimento na modalidade telessaúde.

\subsection{REGULAMENTAÇÃO DAS ATIVIDADES DE ENSINO}

\subsubsection{Regulamentação pelo Ministério da Educação (MEC)}

As atividades de ensino são regulamentadas pelo MEC. Até o dia 28 de maio de 2020, as atividades de atendimento aos pacientes pelas instituições de ensino superior (IES) estavam vedadas (Portaria do Ministro da Educação 343/2020; 345/2020; 395/2020; 473/2020). No despacho do dia 29 de maio, publicado em 1 de junho de 2020, o Ministro de Estado da Educação homologou, parcialmente, - Parecer Conselho Nacional de Educação (CNE) n 5/2020 (deixa de homologar o item 2.16 do referido Parecer) que permite a substituição das atividades práticas presenciais por atividades não presenciais.

O CNE (parecer $n^{\circ}$ 5/2020) considerou a dificuldade para reposição de forma presencial das atividades de ensino, que foram suspensas mesmo após o final do período de emergência (prejudicando o calendário escolar de 2021 e, talvez, o de 2022); o longo período sem aulas, comprometendo o processo da aprendizagem, a permanência das restrições sanitárias no retorno das atividades presenciais e, diante destas questões, orientou o desenvolvimento de atividades não presenciais em substituição às presenciais. Neste sentido, recomendou que as práticas, estágios ou extensão, possam ser cumpridos à distância.

"A substituição da realização das atividades práticas dos estágios de forma presencial para não presencial, com o uso de meios e tecnologias digitais de informação e comunicação, podem estar associadas, inclusive, às atividades de extensão das instituições e dos cursos de licenciatura e formação de professores". 
A oferta de atividades práticas de forma não presencial dependerá de projeto pedagógico curricular específico para a disciplina, (contendo as metodologias, infraestrutura, interação das áreas e campos de estágios com os ambientes externos onde se darão as práticas do curso) que deverá ser transmitida à Secretaria de Regulação e Supervisão da Educação Superior.

Algumas recomendações no parecer CNE n 5/2020 à educação superior (grifo dos autores):

"... adotar a substituição de atividades presenciais relacionadas à avaliação, processo seletivo, TCC e aulas de laboratório, por atividades não presenciais, considerando o modelo de mediação de tecnologias digitais de informação e comunicação adequado à infraestrutura e interação necessárias";

"... adotar a oferta na modalidade à distância ou não presencial às disciplinas teórico-cognitivas dos cursos da área de saúde, independente do período em que são ofertadas";

"...supervisionar estágios e práticas profissionais na exata medida das possibilidades de ferramentas disponíveis; definir a realização das avaliações de forma remota; adotar regime domiciliar para alunos que testarem positivo ou que sejam do grupo de risco";

"... início das atividades com o calendário de reposição de conteúdos e carga horária de forma presencial e não presencial; estabelecer a oferta de aulas presenciais de forma gradual, em paralelo com processo de reposição; manutenção, a critério dos sistemas e instituições, das atividades de reposição de carga horária de forma não presencial; considerar a continuidade em menor escala do contágio e manter, no encerramento da quarentena, as atividades não presenciais em conjunto com as presenciais, mantendo um retorno paulatino à presencialidade de $25 \%, 75 \%$ e 100\%, distribuídos durante o restante do ano letivo".

\subsubsection{Código de ética, diretrizes curriculares e Projeto Político Pedagógico (PPC) da Fisioterapia}

A atenção à saúde dos pacientes neste momento de pandemia tem sido defendida pelo COFFITO e CREFITOs. Segundo o Código de Ética da Fisioterapia, Resolução 424/2013, há artigos que orientam a atividade dos Fisioterapeutas em momentos adversos como este (grifo dos autores):

"Artigo 9 - Constituem-se deveres fundamentais do fisioterapeuta, segundo sua área e atribuição específica:

I - assumir responsabilidade técnica por serviço de Fisioterapia, em caráter de urgência, quando designado ou quando for o 
único profissional do setor, atendendo a Resolução específica; $V$ - colocar seus serviços profissionais à disposição da comunidade em caso de guerra, catástrofe, epidemia ou crise social, sem pleitear vantagem pessoal incompatível com o princípio de bioética de justiça";

"Artigo 10 - É proibido ao fisioterapeuta:

I - negar a assistência ao ser humano ou à coletividade em caso de indubitável urgência";

"Artigo 15 - É proibido ao fisioterapeuta:

I- abandonaro cliente/paciente/usuário em meio a tratamento, sem a garantia de continuidade de assistência, salvo por motivo relevante";

"Artigo 26 - O fisioterapeuta deve atuar em consonância à política nacional de saúde, promovendo os preceitos da saúde coletiva no desempenho das suasfunções, cargos e cidadania, independentemente de exercer a profissão no setor público ou privado".

Com relação ao PPC do curso de Fisioterapia do CEFID / UDESC, uma questão importante a ser destacada é a de que, embora conste a modalidade como presencial, pode transacionar-se a admissibilidade de atividades de forma remota a partir dos seguintes fundamentos:

- A situação de excepcionalidade que se impõe devido à pandemia;

- As diretrizes da UDESC para os cursos de graduação:

"Diretriz 5. Encorajar o reconhecimento de conhecimentos, habilidades e competências adquiridas fora do ambiente escolar, inclusive as que se referem à experiência profissional julgada relevante para a área de formação considerada."

- A "Concepção de curso e perfil de egresso" descrita no PPC (grifo dos autores):

"Acredita-se que o fisioterapeuta formado pela UDESC tem um perfil profissional consciente do papel social da fisioterapia no contexto social, capacitado a agir de forma multidisciplinar e interdisciplinar, junto à equipe de saúde. Embora generalista, possui em sua formação um diferencial que o habilita a atuar em todos os segmentos de atenção à saúde, com uma visão ampla e global, indissociada do conceito de integralidade do ser. Respeitando os princípios bioéticos e culturais do indivíduo articulados ao contexto social, econômico e regional. Está capacitado a tomar decisões baseadas em evidências, visando à eficácia e custo efetividade de procedimentos e de práticas". 


\begin{abstract}
"Visão empreendedora, permitindo identificar oportunidades de crescimento e aperfeiçoamento profissional nas diversas áreas onde sua atuação seja necessária".

"Compromisso com a vida humana, com o desenvolvimento regional e das comunidades nas quais estiver inserido".
\end{abstract}

\title{
3.3 PRIVACIDADE E SIGILO DE INFORMAÇÕES
}

Deve ressaltar-se que o atendimento à distância por meio de ferramentas digitais é orientado pela LEI GERAL DE PROTEÇÃO DE DADOS PESSOAIS (LGPD 13.709 / 2018) e sua emenda (13.853 / 2019). Essa lei disciplina, inclusive nos meios digitais, as questões relacionadas à privacidade e ao acesso às informações pessoais.

\subsection{POSSIBILIDADES DE ENCAMINHAR MATERIAIS DE ORIENTAÇÃO AOS PACIENTES}

É possível encaminhar aos pacientes documentos contendo orientações, exercícios, contudo é preciso, assim como no atendimento presencial, que estas recomendações sejam endereçadas ao paciente. Deve-se ter cuidado com a divulgação de materiais, pois o COFFITO proibiu a atividade quando não se tem a percepção de quais pessoas podem ter acesso a estas informações (Live CREFITO 4). O formato de orientações não endereçadas é permitido somente para atividades acadêmicas, quando o material é disponibilizado aos alunos e profissionais.

\subsection{COMPROVAÇÃO DE ATENDIMENTO}

Há necessidade de materializar o atendimento, gerando o formulário de consentimento autorizado pelo paciente e pelo registro do prontuário. No caso de planos de saúde, o plano pode especificar a forma como o fisioterapeuta deve realizar a comprovação. Pode-se, ainda, solicitar que o paciente, após o atendimento, confirme a atividade realizada (por Whatsapp, por vídeo, formulário).

\subsection{TERMO DE CONSENTIMENTO E PRONTUÁRIO}

O registro do prontuário deve seguir as normas estabelecidas na Resolução 414/2012 COFFITO, podendo ser no formato digital ou físico. É imprescindível que os dados de contatos e endereços sejam de fácil visualização (no caso de o paciente ter um mal súbito, por exemplo, é preciso saber os contatos dele). 
O termo de consentimento (modelo Anexo 1) deve qualificar o paciente e o profissional (nome, idade, CPF, profissão, endereço) e conter a informação de que autoriza o fisioterapeuta a prestar atendimento na forma de Telefisioterapia. No caso de menor de idade ou incapaz, o termo de consentimento deve conter o nome e assinatura do responsável legal. $O$ termo de consentimento pode ser transformado em formulário e enviado on-line ou mesmo gravado um vídeo pelo paciente, autorizando o atendimento ou fotografado após assinado, entre outras alternativas. Pode ser realizado um termo para a primeira consulta e outros a cada consulta.

Nosatendimentos com grupo de pacientes (máximo 6 pacientes porfisioterapeuta), respaldados pela Resolução COFFITO 444/2014, um termo de consentimento com assinatura por paciente deve ser feito.

\section{FERRAMENTAS}

Cabe aos profissionais, professores ou alunos encontrar as melhores ferramentas para auxiliar no atendimento via digital. Neste contexto, há inúmeras barreiras que devem ser consideradas:

- Questões socioeconômicas do paciente/aluno - impossibilidade de internet, celular, ambiente não adequado para o tratamento;

- Capacitação do profissional/aluno - considerar as limitações do profissional na utilização da ferramenta;

- Capacitação do paciente à utilização da ferramenta escolhida;

- Cuidados à manutenção da privacidade - prontuário, ambiente adequado para 0 atendimento;

- Pacientes inelegíveis para Telefisioterapia - que não queiram ou por qualquer motivo não possam receber esta forma de atendimento;

- Expectativa do paciente relacionada ao atendimento.

A escolha de qual ferramenta será adotada é determinada pelo perfil e limitações de cada paciente/aluno, mas independentemente da plataforma/sistema, cuidados com a privacidade e confidencialidade dos dados do paciente devem sempre estar presentes.

Atualmente, há inúmeras ferramentas no mercado, muitas gratuitas (como regra, menos seguras) e outras pagas (mais seguras). Recomenda-se que, mesmo quando o atendimento ocorrer em plataformas seguras, sejam utilizados termos de uso, aceite e consentimento esclarecido bem formulados, quanto mais na utilização de plataformas menos seguras.

Algumas ferramentas disponíveis: SMS, e-mail, impressão e postagem, telefone e Whatsapp. Há plataformas que organizam salas virtuais (Quadro 2) e, 
ainda, aquelas que auxiliam no agendamento e armazenamento dos prontuários, como o Fitaro App (plataforma de gestão de clientes, prescrição de exercícios e telemonitoramento), $\mathrm{Hi}$ - Healthcare Intelligence (gratuito para o CEFID/UDESC até o final da pandemia), iCLINIC, CLINICWEB.

QuAdRO 2 | PLATAFORMAS QUE AUXILIAM NO CONTATO COM O PACIENTE (SALAS VIRTUAIS)

\begin{tabular}{|c|c|c|c|c|c|}
\hline Ferramentas & $N^{0}$ de pessoas & $\begin{array}{l}\text { Compartilha } \\
\text { tela }\end{array}$ & Chat & Grava reunião & Observação \\
\hline Microsoft Teams & 300 & Sim & Sim & Sim & \\
\hline Google Meet & 250 & Sim & Sim & Sim & Gera relatórios \\
\hline Zoom & 100 & Sim & Sim & Sim & $\begin{array}{l}\text { Restrições relacionadas à } \\
\text { segurança de dados }\end{array}$ \\
\hline Wereby & 4 (versão livre) & Sim & Sim & Sim & Não requer login \\
\hline Skype & 50 & Sim & Sim & Sim & \\
\hline Cisco Webex & 200 & Sim & Sim & Sim & $\begin{array}{l}\text { Não precisa download } \\
\text { Gratuito até o final da pandemia }\end{array}$ \\
\hline
\end{tabular}

Fonte: próprio autor

\section{FACILITADORES E BARREIRAS PARA O USO DE TELEFISIOTERAPIA}

Em uma busca estruturada ao acervo da Pubmed, utilizando os descritores do Medical Subjects Heading ("PhysicalTherapyModalities") AND ("Remote Consultation" OR "Telemedicine" OR "Telerehabilitation") em 21/05/2020, foram levantados 114 artigos científicos em que é abordado este tema para diversas condições de saúde. $\mathrm{Na}$ base Pedro encontrou-se 17 revisões sistemáticas sobre o tema, também enfocando diversas condições de saúde. Os autores destas revisões relatam a existência de poucos estudos de qualidade, o que limita a evidência sobre o tema no momento. No entanto, em todos os estudos é enfatizado o uso dessa modalidade como uma alternativa viável para o cuidado ao paciente, especialmente em casos de recursos limitados e dificuldades de acesso ao serviço. 
Os eventos adversos a esta modalidade de atendimento foram pouco focados nestes estudos, no entanto naqueles em que foram sinalizados, a telefisioterapia foi considerada segura às pessoas com sequela de AVE (agudo, subagudo e crônico), doenças cardíacas (leve, moderada) e doenças musculoesqueléticas. As evidências mais robustas são da reabilitação cardíaca.

Identificamos que a telefisioterapia ainda é um campo a ser explorado, onde há poucas respostas ao direcionamento da prática com base em evidências. Assim, consideramos que o uso desta modalidade requer do terapeuta constante atualização (através de estudos da legislação e de formação continuada) para avaliar fatores que impactam de alguma maneira nos atendimentos. Abaixo listamos sugestões de itens a serem considerados.

\subsection{FACILITADORES PARA TELEFISIOTERAPIA}

De maneira geral, os seguintes fatores favorecem a telefisioterapia:

\subsubsection{Recursos tecnológicos}

Para cada um dos recursos disponíveis, sugerimos os seguintes critérios:

- Telefone: possuir acesso com condições de conexão para receber chamadas;

- Orientações assíncronas (por áudios, vídeos ou material informativo): possuir acesso a um computador, tablet ou celular com conexão de internet que suporte navegação e/ou com espaço de armazenamento de dados para download de arquivos grandes;

- Videochamada (síncrono): possuir acesso a um computador, tablet ou celular com câmera e microfone, bem como conexão de internet que suporte a troca de dados.

É recomendado o uso de plataformas digitais específicas para telefisioterapia (vide item 4). Todavia, vale ressaltar que terapeuta e paciente precisarão considerar as condições que viabilizarão o atendimento, tendo em vista a melhor segurança possível ao utilizar o recurso que estiver disponível (Anexo 2).

\subsubsection{Fatores ambientais}

A disponibilidade de um lugar tranquilo para realizar a chamada pode oferecer maior qualidade do atendimento. O terapeuta deve identificar se é necessário fornecer aos pacientes orientações específicas de como utilizar os recursos tecnológicos, garantindo que as suas funcionalidades sejam usadas. Para alguns pacientes, pode ser 
importante alguma explanação sobre como se posicionar e posicionar o computador/ tablet/celular, a fim de que o campo de visão do terapeuta abranja toda a área que o paciente utilizará para se movimentar. Do mesmo modo, o dispositivo deve ser posicionado de tal forma que o paciente possa visualizar a tela e escutar o terapeuta enquanto fornece as orientações.

\subsubsection{Fatores pessoais}

Podem se beneficiar de telefisioterapia pacientes que necessitem de aconselhamento, educação, tratamento de modificação de comportamento, monitoramento das atividades e suporte contínuo. Para tanto, devem ser considerados dados sociodemográficos dos pacientes e quaisquer outras barreiras associadas, como idioma, comunicação, fatores culturais e ambientais, além do acesso e familiaridade com a tecnologia.

O paciente deve apresentar uma condição clínica estável. Além disso, este ou familiar/cuidador deve ter um grau de compreensão suficiente para fornecer o consentimento e pactuar a maneira como a telefisioterapia será realizada.

Em alguns casos, faz-se necessária uma avaliação mais específica do paciente. Para isso, o terapeuta deve verificar se o mesmo possui um familiar/cuidador que possa auxiliá-lo no momento da avaliação, de maneira a obter dados mais fidedignos (p.ex., para monitorar a frequência cardíaca) e a garantir a segurança do paciente (p.ex., para testar equilíbrio).

Pacientes com doenças crônicas podem se beneficiar do telemonitoramento para permitir a identificação de exacerbações precoces e proporcionar educação e orientação à distância. O terapeuta deve considerar o uso de equipamentos de monitorização (p.ex. oxímetro de pulso), caso o paciente já os tenha em casa.

\subsection{BARREIRAS PARA O USO DE TELEFISIOTERAPIA}

Alguns indicativos que sugerem o não uso de Telefisioterapia são:

- Pacientes em condições potencialmente graves e de risco elevado que, provavelmente, precisam de um exame físico para o monitoramento da condição de saúde;

- Casos em que um exame presencial (p.ex., exame ginecológico) não seja necessário;

- Pacientes com comorbidades que afetem sua capacidade para usar a tecnologia (p. ex. confusão, a menos que possa contar com auxílio de familiares/ cuidadores);

- Pacientes que apresentem ansiedade sobre a tecnologia (a menos que possa contar com auxílio de familiares/cuidadores);

Para as pessoas com deficiência as questões relacionadas à segurança (física, 
emocional e de seus direitos) devem ser enfatizadas, especialmente, as que não possuem cuidador. Apresentamos, como exemplo, as pessoas com surdez ou dificuldades auditivas. As que não possuírem intérprete e não conseguirem ler lábios e/ou utilizar a conversa escrita podem se beneficiar das orientações assíncronas, devendo-se evitar as videochamadas.

\section{REGULAÇÃO DOS PACIENTES}

Para que se possa estabelecer o fluxograma para o atendimento à distância nas disciplinas do curso de Fisioterapia CEFID/UDESC, é necessário avaliar a viabilidade de regulação do acesso dos pacientes. A regulação citada, nesse relatório, referese ao perfil de pacientes e o processo de seleção e inclusão na modalidade de telefisioterapia. Com o intuito de compreender tal viabilidade e as especificidades nos campos de práticas vinculados às disciplinas, realizamos um levantamento de dados com os professores que atuam nas disciplinas da sexta à oitava fase do curso (os estágios não foram incluídos nessa etapa e serão analisados posteriormente, caso amodalidade seja implementada).

Para a coleta das informações, um questionário foi enviado a um dos professores de cada disciplina, responsável por intermediar a consulta com os demais (caso a disciplina fosse compartilhada por mais de um professor). O questionário (Anexo 3) apresentava quatro perguntas relacionadas ao perfil de pacientes que poderiam ser regulados para telefisioterapia, percentual de pacientes da disciplina elegíveis à modalidade, informações sobre o responsável pela regulação dos pacientes no campo de prática e possibilidade de acesso remoto aos dados daqueles à regulação.

O levantamento foi realizado com 11 disciplinas. No entanto, para a análise, as disciplinas: Fisioterapia Ortopédica e Traumatológica na Saúde do Adulto e do Idoso 1 e 2, Fisioterapia Uroginecológica e Obstétrica na Saúde do Adulto e do Idoso 1 e 2 e Fisioterapia Cardiorrespiratória na Saúde do Adulto e do Idoso 2, foram subdivididas nos campos de prática (hospitais, ambulatório, Clínica Escola) em função da especificidade de cada local. Dessa forma, foram incluídas na análise 17 campos de prática com atendimento de pacientes (Anexo 4).

A maioria apresentou possibilidades de ofertar parte dos atendimentos na modalidade de Telefisioterapia, sendo excluída essa possibilidade nas unidades hospitalares (especificamente nas unidades de internação) e na disciplina de Prática Integradora da Criança e do Adolescente. Em uma das disciplinas também foi declarada a impossibilidade de estimar o percentual, pois a organização das atividades depende dos profissionais que atuam no serviço. No gráfico abaixo, apresenta-se a distribuição das disciplinas, de acordo com o percentual de pacientes que poderiam receber algum tipo de atendimento, acompanhamento ou monitoramento através de telefisioterapia.

Embora tenham apontado o percentual estimado de pacientes elegíveis para 


\section{GRÁFICO 1 | DISTRIBUIÇÃO DOS CAMPOS DE PRÁTICA DE ACORDO COM O PERCENTUAL DE PACIENTES QUE PODEM SER REGULADOS PARA TELEFISIOTERAPIA POR DISCIPLINA $(\mathrm{N}=16)$}

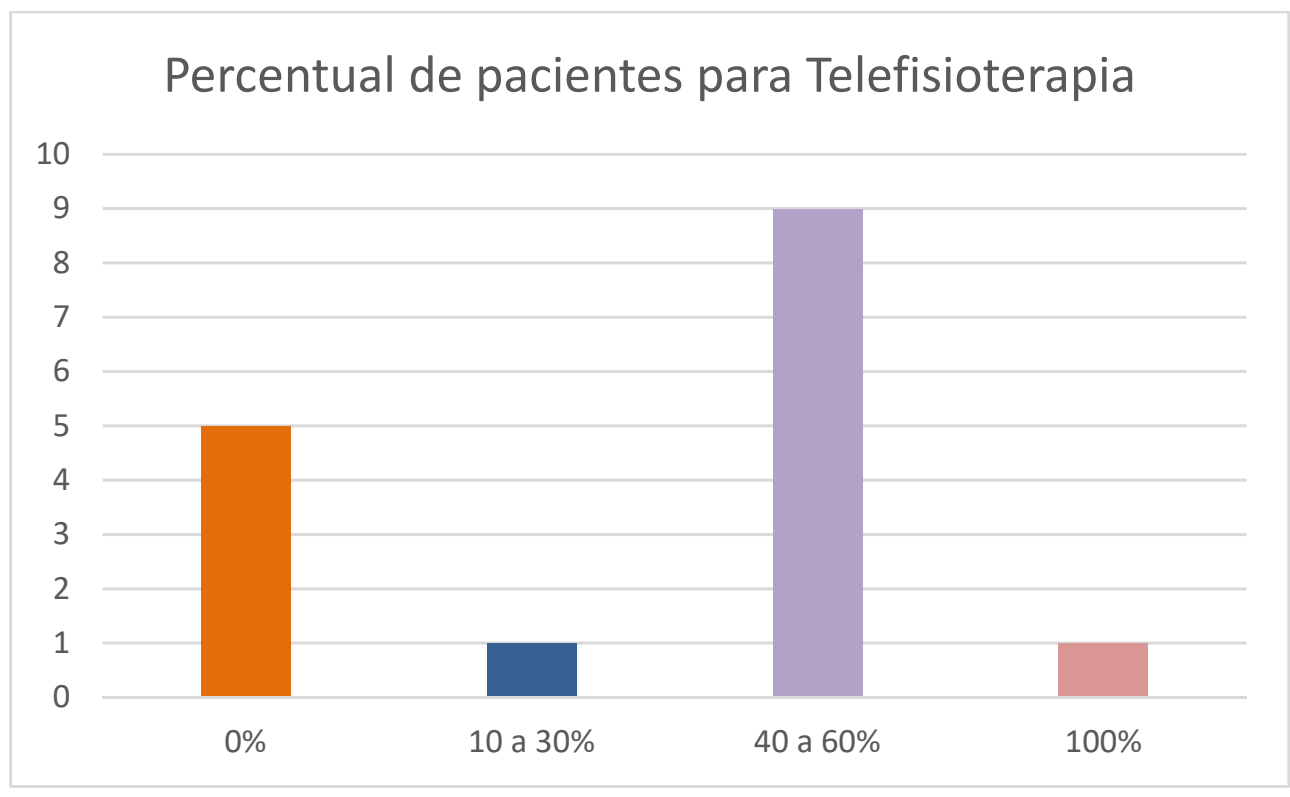

Fonte: próprio autor

telefisioterapia, algumas considerações foram relatadas em função das características da disciplina:

a) As disciplinas da sexta fase são o primeiro contato dos discentes com pacientes. Os professores costumam iniciar pelos conteúdos teóricos a fim de obter melhor preparo a esse primeiro contato, mas em função da pandemia não puderam trabalhar os conteúdos necessários para um início das atividades práticas. Também, consideram que como os alunos não tiveram nenhum contato com os pacientes, seria inoportuno iniciar a prática diretamente nessa modalidade. Nesse sentido, sugerem a possibilidade de direcionar os casos que poderiam ser atendidos em telefisioterapia para os estágios.

b) Na disciplina de Prática Integradora na Saúde do Adulto e do Idoso I, os professores consideram indispensável o contato presencial no desenvolvimento das habilidades e competências necessárias. Sugerem que a disciplina não ocorra até o retorno presencial (se houver essa possibilidade) ou que os atendimentos na modalidade de telefisioterapia aconteçam apenas aos pacientes que frequentavam os grupos das unidades.

Em relação à viabilidade de regulação, os entrevistados apontam que, em locais como a Clínica Escola de Fisioterapia, Ambulatórios dos Hospitais, Núcleo de Cardiologia, seria viável a interação entre o local da prática e o professor para o levantamento de pacientes e acesso aos dados. Em alguns locais, a viabilidade depende de contato prévio com o serviço. Já, nas unidades de internação hospitalar, os professores consideraram inviável obter as informações, até mesmo pela alta rotatividade de pacientes. 


\section{HABILIDADES E COMPETÊNCIAS NECESSÁRIAS AO PROFESSOR E AO ALUNO QUE ATUARÃO COM TELEFISIOTERAPIA}

As estratégias de ensino e competências, normalmente, trabalhadas e avaliadas em atendimentos presenciais devem ser repensadas e outras habilidades incentivadas, pois o avaliar e atender à distância são desafiadores aos profissionais que são normalmente dependentes do contato físico.

Acredita-se que seja indispensável olhar, mais do que nunca, o paciente como um todo (ambiente em que vive, pessoas que dividem a casa, entendimento da informação, questões emocionais, entre muitas outras) e, sobre esta análise elaborar estratégias de educação e promoção da saúde. A escolha das técnicas e métodos não podem mais estar baseados apenas nas especificidades da condição de saúde que é apresentada, ou seja, é necessário a ressignificação de sua condição de saúde com a mesma importância para os cuidados clínicos (cinético funcionais), visando à integração do indivíduo, contexto e ambiente. O paciente deve ser orientado a se perceber, estar ciente das informações prestadas e assumir a responsabilidade sobre o seu cuidado (SUBTIL et al., 2011)

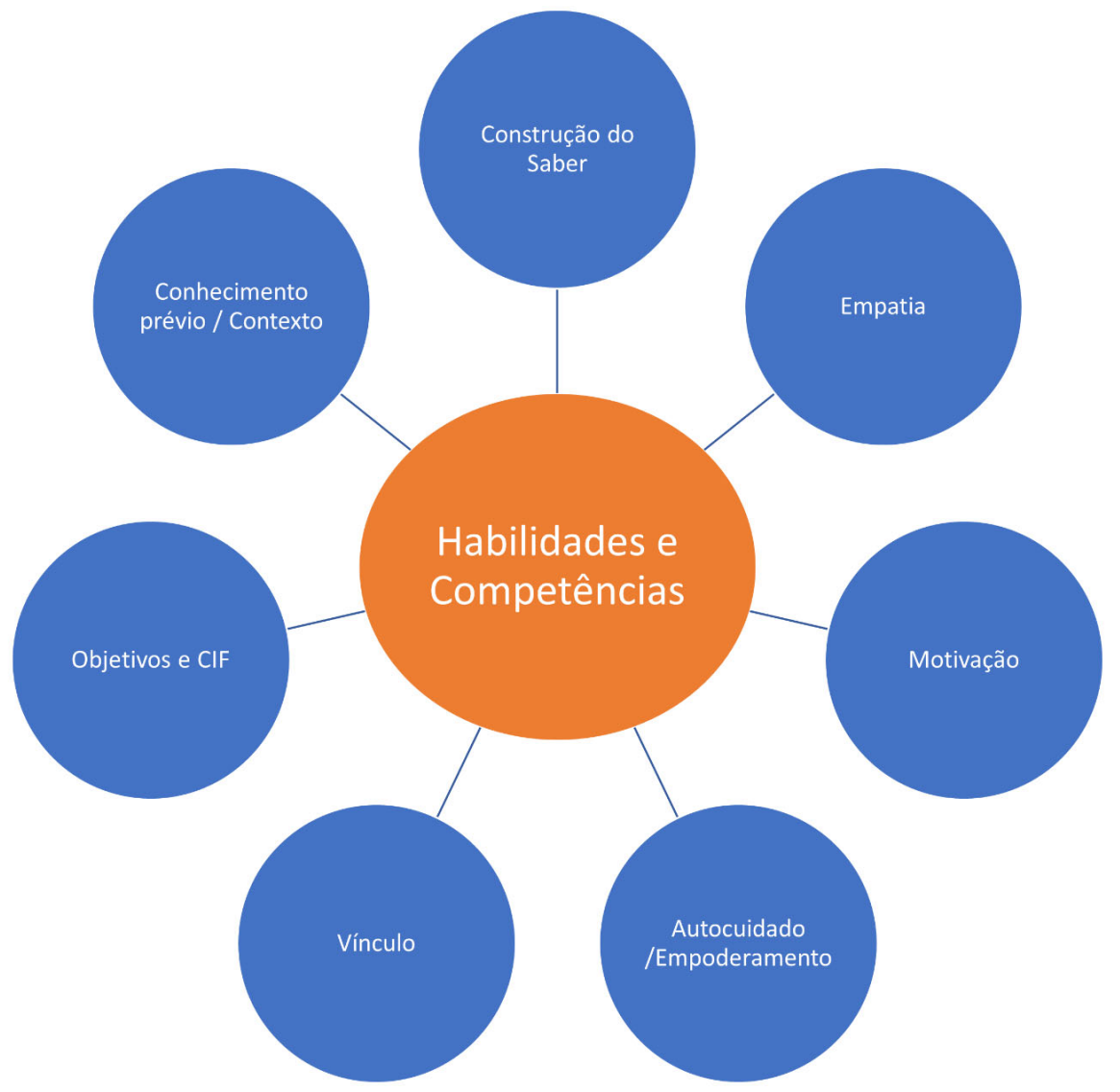

Fonte: próprios autores 


\subsection{CONSTRUÇÃO DE SABER}

O aluno, professor e pacientes devem construir juntos o atendimento, organizando o ambiente à consulta (assegurando a privacidade e segurança de dados), ensinando o paciente no uso da ferramenta (celular, plataforma), buscando materiais e recursos que possam auxiliar no atendimento (exercícios, orientações, recomendações e avaliação), trabalhando o objetivo da sessão.

\subsection{EMPATIA}

É fundamental que professores e alunos trabalhem a compreensão psicoemocional dos complexos fenômenos que envolvem o paciente (contexto de isolamento social, diferenças culturais e nas condições socioeconômicas). É importante que o fisioterapeuta, o professor e o aluno reflitam como é a situação atual que cada um está vivendo, é preciso desenvolver o "escutar o outro", pois muitas atividades propostas durante o atendimento podem não ter o efeito esperado por dificuldades emocionais, motivacionais ou econômicas.

\subsection{MOTIVAÇ̃̃O}

Motivação depende de crenças pessoais em relação ao sucesso e falhas, de enxergar ganhos pessoais ou de valores (seja baseado no interesse, no custo ou na utilidade) na realização de determinada ação (COOK; ARTINO, 2016).

Atualmente, entende-se que a motivação não depende apenas do indivíduo, mas também de suas interações sociais, de suas crenças, do contexto e do ambiente. Há 5 principais Teorias em que a motivação é discutida: "Expectancy-value theories", "Attribution theory", "Social-cognitive theory", "Goal orientation (achievement goal) theories", "Self-determination theory". É fundamental entendermos um pouco de cada teoria para que possamos aplicar em nossos pacientes a motivação da forma mais adequada (COOK; ARTINO, 2016).

1. "Expectancy-value theories" • crenças motivacionais que se enquadram em três grandes categorias: objetivos, autoconceito e dificuldade da tarefa. Exemplo: se eu não acredito que conseguirei ter sucesso em uma tarefa, antecipadamente, nem começo a tarefa.

2. "Attribution theory" • necessidade de entender a causa $x$ efeito das situações cotidianas, sendo motivados por estas necessidades.

3. "Social-cognitive theory" • afirma que as pessoas aprendem através de interações recíprocas com seu ambiente e observando os outros e não, simplesmente, por meio de reforço direto de comportamentos. O desempenho humano (autoeficácia) resulta de interações recíprocas entre três fatores: pessoal (por exemplo, 
crenças, expectativas, atitudes e biologia), comportamental e ambiental. Se o paciente acreditar que é capaz de realizar Telefisioterapia, sentir-se-á mais seguro, motivado e capaz de realizá-lo, tendo uma chance maior de sucesso. A interpretação das experiências prévias influencia na autoeficácia, pois, geralmente, o sucesso a reforça, enquanto as falhas a enfraquecem.

Outro importante modelador da motivação é a persuasão (incentivo verbal) que deve ser utilizado da forma correta, pois se o fisioterapeuta incentiva o paciente a realizar uma tarefa impossível de sucesso para aquele momento, o paciente se sentirá frustrado, levando a uma diminuição de sua autoeficácia e da capacidade de credibilidade. No entanto, se a persuasão for utilizada da forma correta, auxiliará no aumento da autoeficácia e da motivação.

4. "Goal orientation (achievement goal) theories" • inteligência ou habilidade podem aumentar com a aprendizagem. "No pain, no gain", ou seja, é necessário muito esforço para melhorar ou ficar mais inteligente. Pequenos ganhos ou nenhum ganho servem de motivação para tentar melhorar onde erraram. Quanto mais difícil o desafio, mais motivador pode ser.

5. "Self-determinationtheory" • A motivação intrínseca leva a conquistas, todavia, é importante identificar que há objetivos que não necessariamente são de interesse pessoal, mas sim de fatores externos (por exemplo, posição social, trabalho, penalidades), os quais podem levar a uma diminuição da motivação intrínseca.

Três necessidades psicossociais básicas promoverão motivação: autonomia (a oportunidade de controlar ações), competência (autoeficácia) e relacionamento (um sentimento de afiliação ou pertencimento a outros, que alguém sente ou gostaria de se sentir conectado) (COOK; ARTINO, 2016).

A partir da identificação destas teorias, é importante que o professor reflita e tente identificar o que melhor motiva o aluno e o paciente (qual teoria se encaixaria melhor com o perfil?). Após esta identificação é fundamental que trabalhe com esta habilidade com o aluno para que ele, por sua vez, motive o paciente a realizar e a ter sucesso em telefisioterapia.

É meritório o entendimento de que todo aluno/paciente, antes de iniciar qualquer tarefa tenha um conceito prévio, experiências passadas, aptidões e suportes sociais. A autoeficácia é um motivador individual que depende de interações com o ambiente/pessoas, sendo que experiências passadas de sucesso aumentam a autoeficácia, enquanto as falhas diminuem. É importante também identificar: o comando verbal - persuasão - como um incentivador se é usado adequadamente (desafio ou pequenos "passos"); os medos e receio; acontecimentos que atrapalhem o sucesso do atendimento (fatores ambientais); objetivos a curto e longo prazo (para gerar motivação tanto a curto como em longo prazo - detalhados mais à frente no texto) (WILLIAMS; RHODES; ISLAND, 2017).

Para muitas pessoas, o uso da tecnologia (telefisioterapia) pode ser um motivador (motivação extrínseca) que estimula, por sua vez, a autonomia e a competência do paciente (autoeficácia). 


\subsection{AUTOCUIDADO EAUTONOMIA}

Outra questão importante a ser trabalhada é a eficácia da autorregulação, isto é, estimular o paciente a manter a regularidade nas atividades de autocuidado (como, por exemplo, fazer exercícios regularmente), mesmo tendo outros desafios como cobrança de trabalho, cansaço, atividades mais prazerosas, etc.

É valioso empoderar o paciente e sua família em relação à condição de saúde do paciente. Para tanto, é necessário explicar ao paciente que o responsável pela sua própria saúde é ele mesmo. Somente ele poderá cuidar da sua alimentação, das atividades físicas regulares, evitar vícios prejudiciais, entre outros. Realizar atividades que visem ao autocuidado e ao cuidado centrado no paciente e sua família são estratégias para o sucesso do atendimento remoto. Entretanto, é importante salientar que este não é um caminho simples, é necessário dar ferramentas e motivação para que, assim, o paciente compreenda e realize.

Aplicativos, blogs, mídias sociais podem auxiliar neste entendimento sobre o empoderamento do paciente, pois alguns aplicativos vão deixá-lo mais autônomo para compreender o que ocorre com sua própria saúde, bem como outras mídias auxiliarão na mudança de alguns paradigmas relacionados à sua saúde física e mental.

Trabalhar a autonomia do paciente no cuidado da sua saúde pode ocorrer através de orientações às mudanças no estilo de vida (prática de atividade física, tarefas e exercícios específicos, alimentação, qualidade do sono, mudanças na postura, etc.), prevenindo com isto complicações futuras e/ou controlando o processo da doença.

Essa abordagem que exige do paciente o protagonismo no cuidado da sua saúde permite ao professor trabalhar as competências do aluno para além do papel do fisioterapeuta especialista, mas também na formação de um profissional generalista.

\subsection{VÍNCULO}

Para o sucesso de telefisioterapia, é imprescindível estabelecer forte vínculo com o paciente, criando um ambiente em que ele se sinta acolhido, seguro, compreendido. Quando o paciente não se sente julgado, ele compartilha histórias e momentos que podem ser importantes à compreensão da condição de sua saúde pelo fisioterapeuta.

\subsection{OBJETIVOS E CIF}

Como dito anteriormente, para o sucesso e adesão em Telefisioterapia, assim como ocorre em uma sessão de Fisioterapia presencial, é essencial que os objetivos de tratamento sejam selecionados juntamente com o paciente para que ele se sinta motivado.

Os objetivos devem ser específicos, mensuráveis, atingíveis e relevantes. É fundamental os de curto prazo para que o paciente consiga enxergar a melhora e 
se sinta motivado a continuar o tratamento. Aqueles de médio e longo prazo são importantes para que o paciente se sinta incentivado a novas conquistas, ou seja, os objetivos poderão ser divididos em tempos a serem realizados, a fim de que o paciente consiga enxergar como o tratamento é encaminhado e, portanto, sinta-se motivado a continuar. Será determinante para o sucesso do tratamento que estes objetivos sejam atingíveis e relevantes ao contexto de cada paciente.

Para melhor entendimento do contexto do paciente, a avaliação fundamentada na CIF (Classificação Internacional da Funcionalidade) deve ocorrer em todas as áreas. A avaliação baseada no ambiente e participação do paciente facilitará o entendimento do contexto em que se encontra. Esta faz ainda mais sentido em telefisioterapia, visto que o fisioterapeuta estará visualizando como é a casa em que o paciente vive, quais as pessoas com quem convive, quais são as limitações do contexto, quais são as barreiras e facilitadores. Percebendo, ainda, a dificuldade de se quantificar uma avaliação física, é possível realizar a quantificação da avaliação por meio da CIF pelo seu manual ou por aplicativo para móbile (App do CREFITO 4).

\subsection{VALORIZACCÃO DO CONHECIMENTO PRÉVIO/CONTEXTO}

É de grande valia ter um conhecimento do perfil do paciente que será trabalhado: idade, escolaridade, ambiente em que vive (sozinho? ambiente inadequado?), acesso e velocidade da internet, conhecimentos prévios de internet (escolha estratégia: texto, uso de e-mail, videochamada, imagem/GIF/vídeo de orientações e exercícios, folder/cartilha, diários on-line para feedback ao profissional). Além disso, devem ser investigadas as informações relacionadas ao seu processo da condição de saúde, à prática de exercícios prévios (ao ar livre, em casa, clínicas), hobbies, participação na comunidade (profissão, grupos, igreja, etc.).

\subsection{ELEMENTOS DE COMUNICAÇÃO}

Considerando o processo comunicacional adequado como vital para o profissional de saúde e percebendo a tecnologia inserida no contexto do cuidado, torna-se fundamental a compreensão dos fatores comunicacionais na telefisioterapia.

A influência de telefisioterapia sobre a natureza e o conteúdo da comunicação entre equipe de saúde e o paciente decorre, tanto da sua técnica como de seus aspectos interpessoais. É preciso trabalhar estas habilidades para que não ocorra despersonalização da relação paciente $x$ fisioterapeuta, bem como não se percam informações decorrentes das limitações sensoriais, que não captam as comunicações não verbais durante o atendimento remoto.

A separação física entre o fisioterapeuta e o paciente em telefisioterapia pode comprometer a riqueza e a complexidade do contato visual, do olhar, da postura, expressões faciais, do posicionamento do corpo, ou seja, de "pistas" que poderiam modificar o significado de expressões verbais e outras estratégias que devem ser desenvolvidas. 


\subsection{CONHECIMENTO TÉCNICO E EMBASAMENTO CIENTíFICO}

Este critério é indispensável no atendimento realizado à distância, embora também o seja no atendimento presencial. Conhecimento e embasamento científico devem nortear toda tomada de decisão do fisioterapeuta. Neste documento não será abordado de forma aprofundada este critério, porque os docentes já o desenvolviam nas aulas presenciais.

\section{PLANO DE TRATAMENTO EM TELEFISIOTERAPIA}

Após a regulação, ou seja, selecionados os pacientes aptos ao atendimento remoto, deve-se obter o consentimento do paciente para o tratamento (consentimento por escrito via formulário, vídeo do paciente, entre outros). A identificação completa e a anamnese são requisitos para que se cumpram os critérios mínimos no preenchimento do prontuário - Resolução 414/2012 COFFITO - e devem ser devidamente registrados, assim como todo o plano de tratamento, que envolve ações de avaliação, definição de objetivos e seleção de condutas. O modelo biopsicossocial e a CIF são aplicáveis à telefisioterapia e, portanto, recomendados como norteadores do cuidado.

Muitos dos instrumentos de medida que rotineiramente eram usados na avaliação presencial têm seu uso comprometido em Telefisioterapia e, sendo assim, outras análises e testes devem ser adotados. Para tanto, o terapeuta precisará se atualizar com a literatura mais recente disponível. Acredita-se que a CIF deve ser a norteadora dos procedimentos e objetivos. Outros testes podem ser utilizados, dependendo, claro, do conhecimento, habilidades e condições psicofísicas do paciente.

Recomenda-se o estabelecimento dos objetivos do atendimento desde os primeiros encontros, sendo uma construção conjunta com os pacientes. Ressalta-se que estes objetivos podem ser modificados de acordo com a necessidade, levando em consideração a avaliação e motivação do paciente.

A escolha da conduta terapêutica deve ser planejada de forma que a comunicação/ orientação seja clara e precisa para o paciente. $O$ terapeuta deve ter conhecimento de um repertório de estratégias diversificadas, de maneira que possa adaptar a conduta à especificidade de cada um. A característica a ser considerada na seleção das condutas é a motivação do paciente, uma vez que os recursos disponíveis em casa podem ser diferentes e se apresentarem como barreiras à realização do movimento. Além disso, o monitoramento da execução do movimento deve ser realizado de maneira atenta durante o atendimento.

É importante considerar a continuidade do atendimento do paciente. Isto pode ser realizado por meio de materiais audiovisuais (fotos, vídeos, GIF, folders, impressões, apps), contendo orientações, informações, exercícios, etc. que podem ser utilizados como forma de reforçar o aprendizado e incentivar o paciente para que consiga realizar as atividades mesmo na ausência do terapeuta. 
O monitoramento regular do paciente é altamente recomendável a fim de que os objetivos do tratamento sejam atingidos. Este monitoramento pode ser realizado por meio de diários de exercícios, questionários breves ou ligações entre as sessões de atendimento, por exemplo. Da mesma maneira, sugere-se que o terapeuta realize uma autoavaliação do seu desempenho no atendimento, tendo por objetivo o aperfeiçoamento de sua prática.

Para a avaliação do atendimento como um todo, sugere-se que o terapeuta documente no prontuário os comandos de voz utilizados e demais impressões, como o ambiente, o contexto, o estado emocional percebido, o índice de motivação do paciente, etc.

Ao término da sessão, sugere-se que o paciente envie uma confirmação do atendimento para o terapeuta, que pode ser feita por meio de uma mensagem de texto ou vídeo a fim de comprovação do atendimento em prontuário.

A partir destas recomendações e com o objetivo de exemplificar como o atendimento pode ser realizado, apresentamos um modelo de roteiro para a telefisioterapia (Anexo 5).

\section{ORIENTAÇÃO/SUPERVISÃO E AVALIAÇÃO DE ALUNOS}

Esta questão é a mais desafiadora, pois determina a necessidade do professor de estabelecer novos critérios e avaliar competências diferentes daquelas já conhecidas. Nesta modalidade não é possível estar com os alunos o tempo inteiro do atendimento. Há de se considerar que a presença do professor pode constranger paciente e aluno durante o atendimento ou, ao contrário, motivá-los. Cada caso deverá ser analisado pelo professor, que escolherá a melhor maneira de acompanhar a evolução do aluno e paciente.

A escolha da ferramenta, do horário de atendimento e o tempo de atendimento devem ser flexibilizados, uma vez que alunos, professores e pacientes podem ter contextos não muito favoráveis aos atendimentos (ter acesso limitado à internet, ambiente com várias pessoas, espaço físico reduzido, materiais não adequados e outros).

Algumas estratégias de avaliação do processo ensino-aprendizagem que podem auxiliar o professor são: reuniões com os alunos havendo discussões dos casos e das condutas, treinamento do atendimento com o colega (simulação da sala de atendimento), análise dos prontuários, acompanhamento das sessões, entrevista com o paciente e familiares para analisar a evolução do quadro.

Ressalta-se que os critérios de avaliação devem estar de acordo com as novas habilidades e competências desenvolvidas pelo aluno: se ele apresenta conhecimento técnico e embasamento científico, se o prontuário apresenta uma avaliação apropriada, se o aluno desenvolveu elementos de comunicação indispensáveis à atividade, se conseguiu motivar o paciente. Contudo, diante da impossibilidade do professor acompanhar todas as sessões, é imprescindível que seja trabalhada a habilidade de autonomia no aluno e, também, em contrapartida, de confiança no trabalho do aluno pelo professor.

No Anexo 2 há sugestões úteis para o planejamento das atividades de ensino em que é utilizada a telefisioterapia. 


\section{CONSIDERAÇÕES FINAIS E SUGESTÕES}

Neste momento tão único em que vivemos na pandemia, a telefisioterapia é essencial aos pacientes que se sentem "abandonados" e/ou desmotivados com a sua condição de saúde. É uma mudança de paradigmas, em que se deve estimular a autonomia e o autocuidado, transformando o paciente em protagonista de sua própria saúde.

Além disto, a telefisioterapia pode ser um disparador motivacional ao acadêmico que sofre com os anseios de não estar convivendo com colegas e/ou não estar estudando a profissão que escolheu. Vislumbra-se que o acadêmico estará aprendendo uma modalidade da Fisioterapia que chegou com a pandemia e que permanecerá como uma ferramenta da nossa profissão, conforme as evidências mostradas na literatura.

As habilidades e competências a serem trabalhadas por aluno e professores podem não ser as usuais e tradicionais ao Curso de Fisioterapia, no entanto, são habilidades e competências fundamentais na formação de um fisioterapeuta cidadão mais bem preparado e humanizado.

Acredita-se que é possível e viável o uso de Telefisioterapia nas disciplinas da 6a a 10a fase; para tal é recomendado o uso de alguma plataforma gratuita para agendamento e organização da sala virtual de atendimento como, por exemplo, a $\underline{\mathrm{Hi} \text { - Healthcare }}$ Intelligence e a Cisco webex. Deve-se, contudo, adequar as ferramentas aos usuários, neste caso, a via de (whatsapp, celular, plataforma) como ocorrerá o atendimento remoto dependerá da condição socioeconômica dos pacientes. O preenchimento do termo de consentimento, o cuidado com o sigilo das informações e com o armazenamento dos prontuários são condições indispensáveis a esta atividade.

Por fim, acreditamos que telefisioterapia não substitui o atendimento presencial para os pacientes, nem garante aos alunos as mesmas competências, mas há pacientes que podem ser beneficiados, principalmente neste momento, e alunos que ganhem novas habilidades. 


\section{REFERÊNCIAS}

APTA. Telehealth. Abril, 2020. Disponível em: http://www.apta.org/Telehealth/.

COLKINE, Guía práctica de telerehabilitación para kinesiólogos. Versión 1.0 - 22. Abril de 2020. Disponível em: http://www.ckch.cl/wp-content/uploads/2020/04/ Gui\%CC\%81a-TeleRehabilitacio\%CC\%81n-Colkine-20202-V1-final-1.pdf

COOK, D.A.; ARTINO, A.R. Motivation to learn: an overview of contemporary theories. Medical Education 2016: 50: 997-1014. doi: 10.1111/medu.13074.

COX et al. Telerehabilitation versus traditional centrebased pulmonary rehabilitation for people with chronic respiratory disease: protocol for a randomised controlled tria BMC Pulmonary Medicine, 2018; 18:71. doi.org/10.1186/s12890-018-0646-0

CREFITO2. Telessaúde: consulta online. 2020. Disponível em: http://www.crefito2.gov. br/clientes/crefito2/fotos//TELESSA\%C3\%9ADE.pdf

CSP. COVID-19: guide for rapid implementation of remote consultations.

CSP. Face-to-face or remote consultations: supporting you to make safe decisions about patient contact. 2020.

FLORENTINO, D.M. Telefisioterapia Núcleo Telessaúde Rio de Janeiro. Latin Am J telehealth, Belo Horizonte, 2017; 4 (2): 140-144.

HOLLAND, A. Telephysiotherapy: time to get online. Journal of Physiotherapy, 2017; 63: 193-195

LEE, A.C. et al. Telehealth Physical Therapy in Musculoskeletal Practice. J Orthop Sports Phys Ther, 2018; 48 (10): 736-739. doi:10.2519/jospt.2018.0613

NHS. Specialty guides for patient management during the coronavirus pandemic. 2020, v. 1.

RIMMER, A. I don't feel confident providing remote consultations. What do I need to know? BMJ, 2020; 369. doi: https://doi.org/10.1136/bmj.m1746

SILVA, K.M. TeleFisioterapia: modificando paradigmas na educação. Goldbook inovação Tecnológica em Educação e saúde. Disponível em http:// www.telessaude.uerj.br/resource/goldbook/pdf/8.pdf

UNIVERSIDADE DE OXFORD. Consultas por vídeo: um guia prático. 
WANG, S. Can eHealth Technology Enhance the Patient-Provider Relationship in Rehabilitation? Archives of Physical Medicine and Rehabilitation. 2016; 97: 1403-6 doi: https://doi.org/10.1016/j.apmr.2016.04.002

COOK, D. A.; ARTINO, A. R. Motivation to learn: an overview of contemporary theories. Medical Education, 2016; v. 50, n. 10, p. 997-1014.

LOUREIRO SUBTIL, M. M. et al. O relacionamento interpessoal e a adesão na fisioterapia. Fisioterapia em Movimento, 2011; v. 24, n. 4, p. 745-753.

WILLIAMS, D.; RHODES, R. E.; ISLAND, R. The Confounded Self-Efficacy Construct: Review, Conceptual Analysis, and Recommendations for Future ResearchHHS Public Access. HHS Public Access, 2017; v. 10, n. 2, p. 113-128.

WCPT, INPTRA. Report of the WCPT/INPTRA digital physical therapy practice task force, 2019 , v. 7.

SUBTIL, MML; GOES, DC; GOMES, TC; SOUZA, ML. O relacionamento interpessoal e a adesão na fisioterapia. Fisioter. Mov., 2011; vol. 24 no 4. 


\section{ANEXO 1}

MOdelo de TERMO DE CONSENTIMENTO | SUGESTÃO PARA USO EM ATIVIDADES DE ENSINO

\section{TERMO DE CONSENTIMENTO ESCLARECIDO DO CLIENTE/PACIENTE PARA TELECONSULTA/TELEMONITORAMENTO NA FISIOTERAPIA}

Telefisioterapiacorrespondeaoatendimentoàdistância, realizadopelo Fisioterapeuta, usando tecnologias. O Fisioterapeuta pode avaliá-lo, fazer seu diagnóstico cinéticofuncional, estabelecer atividades de orientação, exercícios, entre outras condutas. Ainda, o Fisioterapeuta fará o monitoramento da sua evolução.

Eu, CPF nacionalidade estado civil profissão ,residenteà Complemento , Bairro , localizado no município de /SC, nesta data com __-__. anos de idade, DECLARO, estando em pleno gozo de minhas faculdades mentais, que fui previamente informado por meu/minha fisioterapeuta, $\operatorname{Dr}(a)$. registrado (a) no CREFITOsob o no acerca do meu estado de saúde funcional, bem como declaro, também, que recebi deste(a) todos os esclarecimentos necessários no que se refere ao diagnóstico fisioterapêutico e/ou os objetivos da assistência fisioterapêutica para o tratamento ao qual irei me submeter, tendo este cumprido o dever que Ihe é imposto da Resolução COFFITO no 516/2020 que assegura a Teleconsulta, Telemonitoramento e Teleconsultoria por conta da pandemia do COVID-19. O atendimento ocorrerá de forma virtual, com a participação do (a) acadêmico (a) do curso de Fisioterapia da UDESC matrícula

sob a supervisão de um Fisioterapeuta. Declaro, ainda, ter sido informado (a), de forma clara acerca da finalidade, riscos e benefícios de referido tratamento. Assim sendo, concordo em me submeter ao tratamento proposto e, para tanto, assino o presente documento.

de de (cidade/estado, data)

Nome:

Assinatura: 


\section{ANEXO 2}

MODELO DE CHECKLIST PARA VERIFICAÇÃO DA ADMISSIBILIDADE DO USO DE TELECONSULTA/TELEMONITORAMENTO NA FISIOTERAPIA EM ATIVIDADES DE ENSINO

\section{Planejamento da atividade de ensino \\ Sim Não Observações \\ Orientações}

1. Ferramentas digitais adequadas

\begin{tabular}{|l|l|l|l|l|}
\hline a. Professor & & & & \\
\hline b. Aluno & & & & \\
\hline
\end{tabular}

2. Ambiente adequado (luz, ruídos, privacidade)

a. Professor

b. Aluno

3. Disponibilidade de tempo para o preparo

\begin{tabular}{|l|l|l|l|l|}
\hline a. Professor & & & & \\
\hline b. Aluno & & & & \\
\hline $\begin{array}{l}\text { 4. Professor domina os } \\
\text { aspectos da avaliação } \\
\text { do aluno }\end{array}$ & & & & \\
\hline
\end{tabular}

5. Aspectos da avaliação do aluno

\begin{tabular}{|c|c|c|c|c|}
\hline a. Comunicação & & & & \\
\hline $\begin{array}{l}\text { b. Domínio de instrumentos } \\
\text { de avaliação adequados } \\
\text { para uso em atendimento } \\
\text { remoto }\end{array}$ & & & & \\
\hline $\begin{array}{l}\text { c. Domínio da conduta } \\
\text { terapêutica (PBE) }\end{array}$ & & & & \\
\hline $\begin{array}{l}\text { d. Domínio de elementos } \\
\text { para aumentar a aderência } \\
\text { ao tratamento à distância }\end{array}$ & & & & \\
\hline II. Inclusão do paciente & Sim & Não & Observações & Orientações \\
\hline $\begin{array}{l}\text { 1. Interesse no atendimento } \\
\text { remoto }\end{array}$ & & & & \\
\hline $\begin{array}{l}\text { 2. Grau de compreensão } \\
\text { suficiente }\end{array}$ & & & & \\
\hline $\begin{array}{l}\text { 3. Auxiliar para acompanhar a } \\
\text { sessão (cuidador/ familiar) }\end{array}$ & & & & \\
\hline $\begin{array}{l}\text { 4. Doença/condição clínica } \\
\text { estável }\end{array}$ & & & & \\
\hline $\begin{array}{l}\text { 5. Recurso tecnológico } \\
\text { disponível }\end{array}$ & & & & \\
\hline a. Telefone & & & & \\
\hline b. Computador & & & & \\
\hline c. E-mail & & & & \\
\hline
\end{tabular}




\begin{tabular}{|c|c|c|c|c|}
\hline d. Internet & & & & \\
\hline e. Banda larga & & & & \\
\hline $\begin{array}{l}\text { 6. Habilidade e/ou auxílio } \\
\text { para utilização do recurso } \\
\text { tecnológico }\end{array}$ & & & & \\
\hline $\begin{array}{l}\text { 7. Ambiente adequado (ou } \\
\text { com possibilidade para } \\
\text { adequação) }\end{array}$ & & & & \\
\hline $\begin{array}{l}\text { 8. Requer uso de materiais } \\
\text { para a sessão }\end{array}$ & & & & \\
\hline $\begin{array}{l}\text { a. Possui o material } \\
\text { necessário }\end{array}$ & & & & \\
\hline 9. Termo de Consentimento & & & & \\
\hline 10. Agendamento & & & & \\
\hline $\begin{array}{l}\text { 11. Explicação da dinâmica } \\
\text { da sessão }\end{array}$ & & & & \\
\hline III. Execução da sessão & Sim & Não & Observações & Orientações \\
\hline $\begin{array}{l}\text { 1. Explicação do } \\
\text { funcionamento da sessão } \\
\text { online }\end{array}$ & & & & \\
\hline 2. Dados pessoais do paciente & & & & \\
\hline $\begin{array}{l}\text { 3. Contatos em caso de } \\
\text { emergência }\end{array}$ & & & & \\
\hline 4. Plano de tratamento & & & & \\
\hline a. Avaliação & & & & \\
\hline $\begin{array}{l}\text { b. Diagnóstico cinético } \\
\text { funcional }\end{array}$ & & & & \\
\hline $\begin{array}{l}\text { c. Objetivos (construídos e } \\
\text { pactuados em conjunto } \\
\text { com o paciente) }\end{array}$ & & & & \\
\hline $\begin{array}{l}\text { d. Condutas e critérios de } \\
\text { progressão }\end{array}$ & & & & \\
\hline e. Orientações & & & & \\
\hline $\begin{array}{l}\text { f. Há necessidade de } \\
\text { monitoramento entre as } \\
\text { sessões? }\end{array}$ & & & & \\
\hline 5. Esclarecimento de dúvidas & & & & \\
\hline $\begin{array}{l}\text { 6. Agendamento da próxima } \\
\text { sessão }\end{array}$ & & & & \\
\hline $\begin{array}{l}\text { 7. Registro no prontuário } \\
\text { (evolução) da sessão }\end{array}$ & & & & \\
\hline $\begin{array}{l}\text { 8. Obtenção do termo de } \\
\text { realização de sessão }\end{array}$ & & & & \\
\hline
\end{tabular}




\section{ANEXO 3}

\section{Prezado Professor}

Devido ao nosso cenário atual foi criado um grupo de trabalho para estudar a viabilidade de teleconsulta/telemonitoramento na Fisioterapia como uma das alternativas de atividade prática com pacientes.

Para avaliarmos, estudarmos a viabilização e regulação dos pacientes nos diferentes níveis de atenção, precisamos da sua ajuda para levantarmos algumas informações sobre a sua disciplina. Gostaríamos de contar com a sua ajuda para discutir com os demais professores da sua disciplina/eixo e responder as perguntas abaixo:

1. Nome da disciplina:

2. Na sua disciplina, qual o perfil de pacientes que poderiam ser regulados às atividades relacionadas a teleconsulta/telemonitoramento na Fisioterapia?

3. O perfil de pacientes que poderiam ser encaminhados para essa modalidade, corresponde a qual percentual dos pacientes atendidos na forma presencial?

4. No campo de prática (serviços de saúde), quem faz a regulação dos pacientes que serão atendidos na disciplina (regulado pelo sistema, indicação do profissional do serviço, professor faz busca ativa dos pacientes no local de prática)?

5. No seu campo de prática seria possível ter acesso remoto aos dados de pacientes ou a uma lista de pacientes para regulação?

Caso a resposta seja afirmativa, esses dados seriam levantados pelos professores ou encaminhados por alguém do serviço? 


\section{ANEXO 4}

TABELA COM OS DADOS DE REGULAÇÃO DOS PACIENTES DAS FASES 6aㅡ, 7a e 8a dO CURSO DE FISIOTERAPIA CEFID/UDESC

\begin{tabular}{|c|c|c|c|c|c|}
\hline FASE & DISCIPLINA & $\begin{array}{c}\text { Perfil de } \\
\text { pacientes } \\
\text { que poderiam } \\
\text { ser regulados para } \\
\text { a telerreabilitação }\end{array}$ & $\begin{array}{l}\text { Percentual } \\
\text { para } \\
\text { teler- } \\
\text { reabilitação }\end{array}$ & $\begin{array}{l}\text { Responsável } \\
\text { pela regulação } \\
\text { dos pacientes } \\
\text { atendidos na } \\
\text { disciplina }\end{array}$ & $\begin{array}{l}\text { Acesso remoto } \\
\text { aos dados de } \\
\text { pacientes ou a } \\
\text { uma lista de } \\
\text { pacientes para } \\
\text { regulação }\end{array}$ \\
\hline \multirow{4}{*}{ 6a } & $\begin{array}{c}\text { Fisioterapia } \\
\text { Cardiorrespiratória } \\
\text { Saúde da Criança e } \\
\text { do Adolescente }\end{array}$ & $\begin{array}{l}\text { Crianças com } \\
\text { pneumopatia } \\
\text { crônicas - } \\
\text { telemonitoramento. } \\
\text { Já está acontecendo } \\
\text { via extensão }\end{array}$ & $20 \%$ & $\begin{array}{c}\text { Sistema, } \\
\text { Encaminhamento } \\
\text { de outros serviços, } \\
\text { Professor }\end{array}$ & $\begin{array}{c}\text { Sim. } \\
\text { Clínica } \\
\text { Escola de } \\
\text { Fisioterapia }\end{array}$ \\
\hline & $\begin{array}{c}\text { Fisioterapia } \\
\text { Neurologia na } \\
\text { Saúde da Criança } \\
\text { e do Adolescente }\end{array}$ & $\begin{array}{c}\text { Crianças que } \\
\text { ja estavam em } \\
\text { assistência na clínica } \\
\text { - casos de paralisia } \\
\text { cerebral, síndromes, } \\
\text { atrasos globais com } \\
\text { diagnósticos não } \\
\text { definidos, lactentes } \\
\text { (até } 18 m \text { ) com atraso } \\
\text { no desenvolvimento } \\
\text { motor, plagiocefalia, } \\
\text { torcicolo congênito }\end{array}$ & $40 \%$ & Clínica Escola & $\begin{array}{c}\text { Sim. } \\
\text { Clínica } \\
\text { Escola de } \\
\text { Fisioterapia }\end{array}$ \\
\hline & $\begin{array}{c}\text { Fisioterapia } \\
\text { Ortopédica, } \\
\text { traumatológia } \\
\text { e Reumatológica } \\
\text { Saúde da Criança } \\
\text { e do Adolescente }\end{array}$ & $\begin{array}{l}\text { Perfil para } \\
\text { telemonitoramento } \\
\text { - Pacientes que já } \\
\text { realizam há mais de } \\
1 \text { ano fisioterapia } \\
\text { e que estejam em } \\
\text { acompanhamento na } \\
\text { clínica escola por mais } \\
\text { de seis meses, que } \\
\text { apresentam alterações } \\
\text { funcionais leves. } \\
\text { Perfil para Teleconsulta: } \\
\text { Casos agudos - pós- } \\
\text { operatório de cirurgia } \\
\text { ortopédica, pós- } \\
\text { imobilização, fraturas } \\
\text { recentes ou recém- } \\
\text { nascidos e lactentes } \\
\text { com torcicolo muscular } \\
\text { congênito, paralisia } \\
\text { braquial obstétrica, pé } \\
\text { torto congênito }\end{array}$ & $\begin{array}{l}50 a \\
60 \%\end{array}$ & Clínica Escola & $\begin{array}{c}\text { Sim. } \\
\text { Clínica } \\
\text { Escola de } \\
\text { Fisioterapia }\end{array}$ \\
\hline & $\begin{array}{l}\text { Prática Integradora } \\
\text { na Saúde da } \\
\text { Criança e } \\
\text { Adolescente }\end{array}$ & $\begin{array}{l}\text { Não seria possível } \\
\text { telerreabilitação }\end{array}$ & $0 \%$ & Clínica Escola & $\begin{array}{c}\text { Sim. } \\
\text { Clínica } \\
\text { Escola de } \\
\text { Fisioterapia }\end{array}$ \\
\hline
\end{tabular}




\begin{tabular}{|c|c|c|c|c|c|}
\hline FASE & DISCIPLINA & $\begin{array}{c}\text { Perfil de } \\
\text { pacientes } \\
\text { que poderiam } \\
\text { ser regulados para } \\
\text { a telerreabilitação }\end{array}$ & $\begin{array}{l}\text { Percentual } \\
\text { para } \\
\text { teler- } \\
\text { reabilitação }\end{array}$ & $\begin{array}{c}\text { Responsável } \\
\text { pela regulação } \\
\text { dos pacientes } \\
\text { atendidos na } \\
\text { disciplina }\end{array}$ & $\begin{array}{c}\text { Acesso remoto } \\
\text { aos dados de } \\
\text { pacientes ou a } \\
\text { uma lista de } \\
\text { pacientes para } \\
\text { regulação }\end{array}$ \\
\hline \multirow{5}{*}{$7^{\mathrm{a}}$} & \multirow[b]{2}{*}{$\begin{array}{c}\text { Fisioterapia } \\
\text { Ortopédica, } \\
\text { Traumatológica e } \\
\text { reumatológica na } \\
\text { Saúde do Adulto e } \\
\text { do Idoso I }\end{array}$} & $\begin{array}{l}\text { Hospital: Não } \\
\text { seria possível } \\
\text { telerreabilitação }\end{array}$ & $0 \%$ & $\begin{array}{l}\text { Professor e } \\
\text { hospitais do } \\
\text { Serviço }\end{array}$ & $\begin{array}{c}\text { Não. Sistema } \\
\text { de Informação } \\
\text { do Hospital }\end{array}$ \\
\hline & & $\begin{array}{l}\text { Clínica: Tendinopatias } \\
\text { das mais diversas, } \\
\text { Síndrome } \\
\text { Femoropatelar, Fascite } \\
\text { Plantar, Entorses } \\
\text { de Tornozelo, IFA, } \\
\text { Osteoartrose, Dor } \\
\text { Lombar e Cervical } \\
\text { Crônica, Bursites }\end{array}$ & $40-50 \%$ & Clínica Escola & $\begin{array}{c}\text { Sim. } \\
\text { Clínica } \\
\text { Escola de } \\
\text { Fisioterapia }\end{array}$ \\
\hline & $\begin{array}{c}\text { Prática } \\
\text { Integradora na } \\
\text { Saúde do Adulto } \\
\text { e do Idoso I }\end{array}$ & $\begin{array}{l}\text { Adultos e Idosos } \\
\text { com problemas } \\
\text { ortopédicos } \\
\text { crônicos. } \\
\text { Possibilidade de } \\
\text { encaminhar os } \\
\text { pacientes que } \\
\text { estavam sendo } \\
\text { atendidos em grupos }\end{array}$ & $\begin{array}{c}\text { Não há } \\
\text { como estimar } \\
\text { o percentual }\end{array}$ & $\begin{array}{l}\text { Fisioterapeutas } \\
\text { das unidades } \\
\text { de saúde }\end{array}$ & $\begin{array}{c}\text { Não temos } \\
\text { certeza. Existe } \\
\text { a possibilidade } \\
\text { de ser } \\
\text { encaminhado } \\
\text { pelo sistema } \\
\text { de informações } \\
\text { da prefeitura } \\
\text { ou pelos } \\
\text { profissionais - } \\
\text { mas depende } \\
\text { de acordo } \\
\text { prévio com as } \\
\text { unidades }\end{array}$ \\
\hline & \multirow{2}{*}{$\begin{array}{l}\text { Fisioterapia em } \\
\text { Uroginecologia } \\
\text { e Obstetrícia } \\
\text { na Saúde } \\
\text { do Adulto e } \\
\text { do Idoso I }\end{array}$} & $\begin{array}{c}\text { Clínica: } \\
\text { pós-operatório } \\
\text { de câncer de mama } \\
\text { com limitação } \\
\text { de amplitude de } \\
\text { movimento e } \\
\text { linfedema, e gestantes }\end{array}$ & $60 \%$ & Clínica Escola & $\begin{array}{l}\text { Sim. } \\
\text { Clínica } \\
\text { Escola e } \\
\text { Professores }\end{array}$ \\
\hline & & $\begin{array}{l}\text { Hospital: } \\
\text { Não seria possível } \\
\text { telerreabilitação }\end{array}$ & $0 \%$ & $\begin{array}{c}\text { Professor faz a } \\
\text { seleção de acordo } \\
\text { com os prontuários } \\
\text { e necessidade } \\
\text { de atendimento } \\
\text { fisioterapêutico }\end{array}$ & $\begin{array}{l}\text { Acredito } \\
\text { que não }\end{array}$ \\
\hline
\end{tabular}




\begin{tabular}{|c|c|c|c|c|c|}
\hline FASE & DISCIPLINA & $\begin{array}{c}\text { Perfil de } \\
\text { pacientes } \\
\text { que poderiam } \\
\text { ser regulados para } \\
\text { a telerreabilitação }\end{array}$ & $\begin{array}{l}\text { Percentual } \\
\text { para } \\
\text { teler- } \\
\text { reabilitação }\end{array}$ & $\begin{array}{l}\text { Responsável } \\
\text { pela regulação } \\
\text { dos pacientes } \\
\text { atendidos na } \\
\text { disciplina }\end{array}$ & $\begin{array}{l}\text { Acesso remoto } \\
\text { aos dados de } \\
\text { pacientes ou a } \\
\text { uma lista de } \\
\text { pacientes para } \\
\text { regulação }\end{array}$ \\
\hline \multirow{6}{*}{$8{ }^{a}$} & \multirow{3}{*}{$\begin{array}{l}\text { Fisioterapia } \\
\text { Cardiorrespiratória } \\
\text { na Saúde do } \\
\text { Adulto e do } \\
\text { Idoso II }\end{array}$} & $\begin{array}{c}\text { Hospital Regional: } \\
\text { Pacientes em } \\
\text { atendimento na } \\
\text { clínica - Reabilitação } \\
\text { Pulmonar e no } \\
\text { Núcleo de Cardiologia } \\
\text { - Reabilitação } \\
\text { Cardiovascular }\end{array}$ & $50 \%$ & $\begin{array}{c}\text { Conforme } \\
\text { indicação dos } \\
\text { profissionais do } \\
\text { serviço }\end{array}$ & $\begin{array}{l}\text { Acredito } \\
\text { que não } \\
\text { (talvez se a } \\
\text { demanda vier } \\
\text { do próprio } \\
\text { serviço) }\end{array}$ \\
\hline & & $\begin{array}{c}\text { Clínica Escola } \\
\text { e Núcleo de } \\
\text { Cardiologia: } \\
\text { Pacientes atendidos } \\
\text { no ambulatório, } \\
\text { com doenças } \\
\text { respiratórias crônicas } \\
\text { (clínica escola)e } \\
\text { cardiopatas (Núcleo } \\
\text { de Cardiologia) }\end{array}$ & $100 \%$ & $\begin{array}{l}\text { Os pacientes } \\
\text { com doenças } \\
\text { respiratórias } \\
\text { crônicas - } \\
\text { Clínica Escola, e } \\
\text { os cardiopatas } \\
\text { - Núcleo de } \\
\text { Cardiologia }\end{array}$ & $\begin{array}{l}\text { Sim. } \\
\text { Poderia ser } \\
\text { realizado pela } \\
\text { equipe da } \\
\text { Clínica Escola } \\
\text { e no caso dos } \\
\text { cardiopatas a } \\
\text { profa com } \\
\text { visita presencial } \\
\text { ao Núcleo }\end{array}$ \\
\hline & & $\begin{array}{c}\text { Hospital } \\
\text { Florianópolis: } \\
\text { não seria possível } \\
\text { telerreabilitação }\end{array}$ & $0 \%$ & $\begin{array}{l}\text { Professor e } \\
\text { profisisonais } \\
\text { do serviço }\end{array}$ & $\begin{array}{c}\text { Não. } \\
\text { Dificuldade } \\
\text { de acesso aos } \\
\text { dados dos } \\
\text { prontuários }\end{array}$ \\
\hline & $\begin{array}{l}\text { Fisioterapia } \\
\text { Neurológica na } \\
\text { Saúde do Adulto } \\
\text { e do Idoso II }\end{array}$ & $\begin{array}{c}\text { Pacientes com lesões } \\
\text { crônicas que estavam } \\
\text { em atendimento } \\
\text { em } 2019 / 02 \text {, que já } \\
\text { receberam um plano } \\
\text { de atividades para as } \\
\text { férias e orientações } \\
\text { presenciais }\end{array}$ & $40 \%$ & $\begin{array}{l}\text { Clínica Escola } \\
\text { e Professores }\end{array}$ & $\begin{array}{c}\text { Sim. } \\
\text { Clínica } \\
\text { Escola de } \\
\text { Fisioterapia }\end{array}$ \\
\hline & \multirow[b]{2}{*}{$\begin{array}{l}\text { Fisioterapia } \\
\text { Ortopédica, } \\
\text { Traumatológica } \\
\text { e reumatológica } \\
\text { na Saúde do } \\
\text { Adulto e do Idoso II }\end{array}$} & $\begin{array}{l}\text { Hospitais: Não } \\
\text { seria possível } \\
\text { telerreabilitação }\end{array}$ & $0 \%$ & $\begin{array}{l}\text { Professor e } \\
\text { hospitais do } \\
\text { Serviço }\end{array}$ & $\begin{array}{c}\text { Não. } \\
\text { Sistema de } \\
\text { Informação do } \\
\text { Hospital }\end{array}$ \\
\hline & & $\begin{array}{c}\text { Clínica: } \\
\text { Tendinopatias } \\
\text { das mais diversas, } \\
\text { Síndrome } \\
\text { Femoropatelar, } \\
\text { Fascite Plantar, } \\
\text { Entorses de } \\
\text { Tornozelo, Impacto } \\
\text { femoro-acetabular, } \\
\text { Osteoartrose, Dor } \\
\text { Lombar e Cervical } \\
\text { Crônica, Bursites }\end{array}$ & $40-50 \%$ & Clínica Escola & $\begin{array}{c}\text { Sim. } \\
\text { Clínica } \\
\text { Escola de } \\
\text { Fisioterapia }\end{array}$ \\
\hline
\end{tabular}




\begin{tabular}{|c|c|c|c|c|c|}
\hline FASE & DISCIPLINA & $\begin{array}{l}\text { Perfil de } \\
\text { pacientes } \\
\text { que poderiam } \\
\text { ser regulados para } \\
\text { a telerreabilitação }\end{array}$ & $\begin{array}{l}\text { Percentual } \\
\text { para } \\
\text { teler- } \\
\text { reabilitação }\end{array}$ & $\begin{array}{l}\text { Responsável } \\
\text { pela regulação } \\
\text { dos pacientes } \\
\text { atendidos na } \\
\text { disciplina }\end{array}$ & $\begin{array}{l}\text { Acesso remoto } \\
\text { aos dados de } \\
\text { pacientes ou a } \\
\text { uma lista de } \\
\text { pacientes para } \\
\text { regulação }\end{array}$ \\
\hline \multirow[b]{2}{*}{$8^{a}$} & \multirow{2}{*}{$\begin{array}{l}\text { Fisioterapia em } \\
\text { Uroginecologia } \\
\text { e Obstetrícia } \\
\text { na Saúde } \\
\text { do Adulto e } \\
\text { do Idoso II }\end{array}$} & $\begin{array}{l}\text { Hospital: Pacientes } \\
\text { do grupo de } \\
\text { Incontinência Urinária } \\
\text { do Ambulatório }\end{array}$ & $50 \%$ & $\begin{array}{l}\text { Clínica Escola, } \\
\text { Encaminhamentos, } \\
\text { Professor }\end{array}$ & $\begin{array}{c}\text { Sim. } \\
\text { Professor }\end{array}$ \\
\hline & & $\begin{array}{c}\text { Clínica: Pacientes } \\
\text { com incontinência } \\
\text { urinária ou fecal sem } \\
\text { comprometimento } \\
\text { neurológico e } \\
\text { cognitivo. }\end{array}$ & $40 \%$ & Clínica Escola & $\begin{array}{c}\text { Sim. } \\
\text { Clínica } \\
\text { Escola de } \\
\text { Fisioterapia }\end{array}$ \\
\hline
\end{tabular}




\section{ANEXO 5}

SUGESTÃO DE ROTEIRO PARA A REALIZAÇÃO DE TELECONSULTA/TELEMONITORAMENTO NA FISIOTERAPIA

1. PRIMEIRO CONTATO (com o paciente ou familiar/cuidador)

1.1. Questionar sobre o interesse e possibilidade de realizar atendimento remoto;

1.2. Questionar sobre o grau de compreensão do paciente

1.3. Questionar sobre a presença de acompanhante para auxiliar durante a sessão; 1.4. Questionar sobre a condição clínica, investigando se há necessidade de atendimento presencial (atentar para as condições que contraindicariam teleatendimento como, por exemplo, angina instável, hipertensão ou diabetes descompensadas);

1.5. Questionar sobre disponibilidade de recursos tecnológicos (celular, notebook), internet (largura de banda e qualidade da conexão) e uso de e-mail;

1.6. Questionar sobre a capacidade de utilizar o recurso tecnológico (se não houver, pergunte sobre a possibilidade de ajuda de terceiros);

1.7. Orientar sobre o posicionamento do dispositivo de imagem (filmadora, celular, notebook) para facilitar a realização do atendimento;

1.8. Questionar sobre o ambiente à realização da sessão (luminosidade, ruído, cama, cadeira, espaços livres);

1.9. Levantar quais materiais estão disponíveis para a execução das condutas (priorizar materiais simples como faixa de roupão, toalha...);

1.10. Solicitar o consentimento à realização do atendimento remoto (assinatura de um termo ou vídeo do paciente ou responsável);

1.11. Agendamento da sessão;

1.12. Explicar a dinâmica das sessões.

\section{ATENDIMENTO}

2.1. Apresente-se;

2.2. Confirme se a pessoa está lhe ouvindo/vendo bem;

2.3. Questione sobre o estado atual do paciente, buscando identificar possíveis sinais de alerta;

2.4. Certifique-se de que o local em que o paciente se encontra é apropriado para a realização da sessão (observar o espaço, a segurança e a privacidade);

2.5. Realize a sessão conforme planejado;

2.5.1. Na primeira sessão, registrar: dados pessoais do paciente (nome completo, endereço, telefones) e contato em caso de emergência;

2.5.2. Execute a avaliação específica para o caso; 
2.5.3. Em conjunto com o paciente, selecione os objetivos de maneira que sejam específicos, mensuráveis, atingíveis, realísticos e oportunos;

2.5.4. Identifique as necessidades de materiais à realização das consultas (nas sessões subsequentes, solicitar que o material seja preparado para que esteja disponível no momento da sessão);

2.6. Questione as dificuldades apresentadas pelo paciente ou acompanhante;

2.7. Agende o próximo contato (monitoramento ou sessão);

2.8. Solicite o termo de realização da sessão (pode ser um áudio ou vídeo do paciente).

\section{REGISTRO}

3.1. Registre o termo de realização da sessão;

3.2. Registre a data e horário de atendimento no prontuário do paciente, informando que foi realizado de forma remota e indicando o uso do recurso utilizado;

3.3. Registre as dificuldades encontradas e como podem ser solucionadas. 

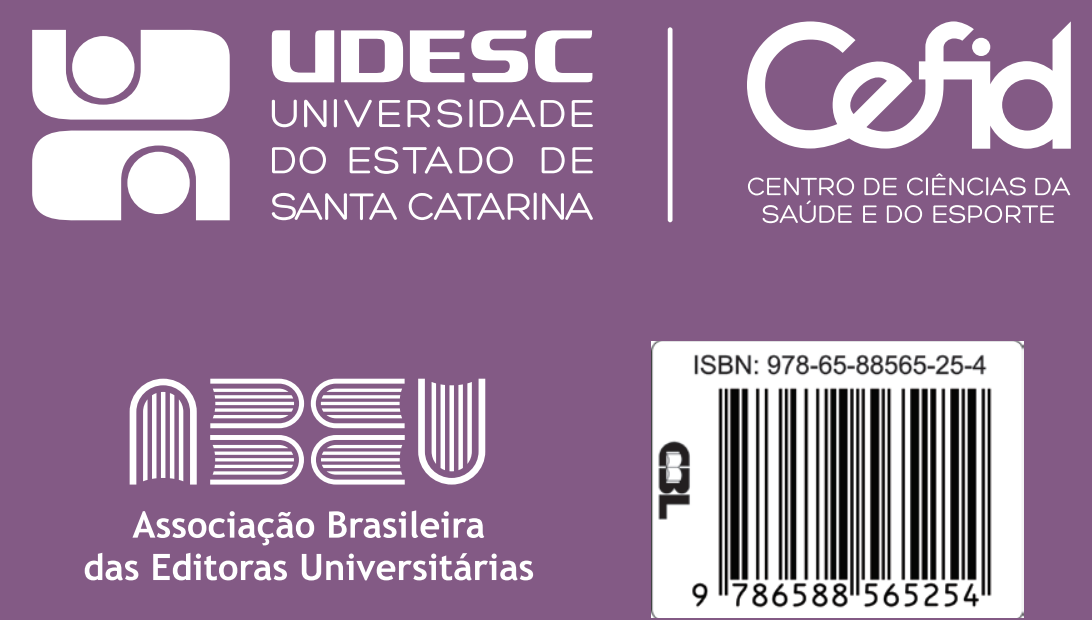